OPEN ACCESS

Edited by:

Xavier Figueroa,

Pontificia Universidad Católica

de Chile, Chile

Reviewed by:

Zoltan I. Ungvari,

The University of Oklahoma Health

Sciences Center, United States

Jillian L. Stobart,

University of Manitoba, Canada

*Correspondence:

Jessica A. Filosa

jfilosa@augusta.edu

Specialty section:

This article was submitted to

Vascular Physiology,

a section of the journal

Frontiers in Physiology

Received: 16 July 2020 Accepted: 04 September 2020 Published: 25 September 2020

Citation:

Presa JL, Saravia F, Bagi $Z$ and Filosa JA (2020) Vasculo-Neuronal Coupling and Neurovascular Coupling at the Neurovascular Unit: Impact of Hypertension.

Front. Physiol. 11:584135. doi: 10.3389/fphys.2020.584135

\section{Vasculo-Neuronal Coupling and Neurovascular Coupling at the Neurovascular Unit: Impact of Hypertension}

\author{
Jessica L. Presa ${ }^{1,2}$, Flavia Saravia ${ }^{2}$, Zsolt Bagi' and Jessica A. Filosa ${ }^{1 *}$ \\ ${ }^{1}$ Department of Physiology, Medical College of Georgia, Augusta University, Augusta, GA, United States, ${ }^{2}$ Departamento \\ de Química Biológica, Facultad de Ciencias Exactas y Naturales, Universidad de Buenos Aires and Instituto de Biología y \\ Medicina Experimental, CONICET, Buenos Aires, Argentina
}

Components of the neurovascular unit (NVU) establish dynamic crosstalk that regulates cerebral blood flow and maintain brain homeostasis. Here, we describe accumulating evidence for cellular elements of the NVU contributing to critical physiological processes such as cerebral autoregulation, neurovascular coupling, and vasculoneuronal coupling. We discuss how alterations in the cellular mechanisms governing NVU homeostasis can lead to pathological changes in which vascular endothelial and smooth muscle cell, pericyte and astrocyte function may play a key role. Because hypertension is a modifiable risk factor for stroke and accelerated cognitive decline in aging, we focus on hypertension-associated changes on cerebral arteriole function and structure, and the molecular mechanisms through which these may contribute to cognitive decline. We gather recent emerging evidence concerning cognitive loss in hypertension and the link with vascular dementia and Alzheimer's disease. Collectively, we summarize how vascular dysfunction, chronic hypoperfusion, oxidative stress, and inflammatory processes can uncouple communication at the NVU impairing cerebral perfusion and contributing to neurodegeneration.

Keywords: neurovascular, astrocyte, cogntive decline, ischemia, pulsatility

\section{THE NEUROVASCULAR UNIT: A GENERAL OVERVIEW}

Blood flow in the brain is directed through a vascular network that links interconnected surface (pial) arteries to penetrating (parenchymal) arterioles and a vast network of capillaries, ultimately draining back to the surface via post-capillary venules and veins. Perfusion within the brain is a highly controlled process maintained through the operation of activity-dependent as well as constitutive mechanisms. Importantly, these mechanisms act in concert to ensure brain homeostasis and optimal functioning.

The brain is a complex functional and structural organizational unit. The smallest level of cellular interactions establishing brain perfusion is the neurovascular unit (NVU) (Iadecola, 2017), which comprises, at minimum, neurons, astrocytes, endothelial cells, vascular smooth muscle cells (VSMCs) and/or pericytes. Dynamic communication among these components contributes to the moment to moment regulation of arteriole and capillary blood flow and provides neurons 
with energy substrates as well as removal of waste metabolites. In the classic view, neuron-to-vessel communication (including via astrocytes), referred to as neurovascular coupling (NVC) and neurometabolic coupling, links increases in neuronal metabolic activity to increases in local blood flow (functional hyperemia). Importantly, interactions at the NVU are also bidirectional, with ongoing vessel-to-neuronal signaling, or vasculo-neuronal coupling (VNC), playing a role in establishing homeostasis at the NVU. In this review, we discuss dynamic signaling pathways at the NVU and how diseases, such as hypertension, affect them leading to cognitive dysfunction and neurodegeneration.

\section{Endothelial Cells}

While the skull protects the brain from the external environment, endothelial cells are the first line of defense against the entrance of blood-borne pathogens, inflammatory-inducing components of the blood and circulating macrophages and are thus important contributors to brain homeostasis. The brain endothelium expresses highly specialized proteins, termed adherens and tight junction proteins, that mediate tight cell-to-cell contacts. These adherens (e.g., cadherins and junctional adhesion molecules) and tight junctions (e.g., occludins and claudins) contribute to formation of the blood-brain barrier (BBB), which maintains the high transendothelial electrical resistance and low paracellular transport properties characteristic of the brain endothelium (Sweeney et al., 2019; De Silva and Faraci, 2020). The basement membrane, comprising a family of proteins called perlecans (Thomsen et al., 2017), surrounds the endothelium and is also involved in homeostasis and maintenance of the BBB as well as communication at the NVU. Proteins of the basement membrane are known targets in disease; when their function is impaired, the integrity of the BBB is disrupted and the passage of molecules is dysregulated (Roberts et al., 2012; Mortensen et al., 2019). Mural cells and astrocytic endfeet surrounding the endothelium further contribute to maintenance of the BBB. In addition, endothelial cells release vasoactive signals, such as nitric oxide (NO), that control vascular resistance and thereby blood flow (Iadecola, 2013). The cellular mechanisms that drive endothelialmediated changes in vascular tone include mechanical forces (e.g., wall shear stress), signals released by neighboring cells and electrical coupling such as endothelium-vascular smooth muscle cell (VSMC) interactions that drive hyperpolarization of the membrane potential of VSMCs, resulting in dilation (Longden et al., 2017). For example, agonist-induced activation of endothelial cell TRPV4 channels [i.e., epoxyeicosatrienoic acids (EETs)] increase calcium leading to the activation of intermediate (IK) and small (SK) conductance $\mathrm{K}^{+}$channels which through myoendothelial junction causes hyperpolarization of VSMCs membrane potential resulting in vasodilation (Sonkusare et al., 2012). In addition, endothelial cells are electrically coupled via gap junctions allowing for the fast conductance of current along the endothelial syncytium, which at the arteriole level can also influence VSMC membrane potential (Figueroa and Duling, 2009; Bagher and Segal, 2011). A critical example of this process, discussed later in the review, is the activation of inwardly rectifying $\mathrm{K}^{+}$(Kir2.1) channels in endothelial cells resulting in the upstream propagation of a hyperpolarizing current and dilation of parenchymal arterioles (Longden et al., 2017). For a detailed review of these mechanisms (see Harraz et al., 2020).

\section{Vascular Smooth Muscle Cells}

As blood moves from larger arterioles downstream toward capillaries and then venules, its flow is regulated by crosstalk among various cells. Zonation-a gradual phenotypic change along the arteriovenous axis-was recently reported based on single-cell transcriptomics studies (Vanlandewijck et al., 2018). When applied to target disease-mediated changes in gene expression, transcriptomic studies such as this may help identify key drivers of small vessel disease and impaired communication at the NVU. In penetrating arterioles, a single layer of VSMCs wraps around the basal lamina, which in turn covers the entire endothelial cell layer. VSMCs play an essential role in the regulation of vascular tone (Hill-Eubanks et al., 2014) and also contribute to arterial elasticity by secreting extracellular matrix proteins (Wight, 2008).

\section{Pericytes}

Pericytes are a pluripotent, perivascular mural cell type that is mainly found covering capillaries. Pericytes are also known to contribute to the maintenance and integrity of the BBB (Sweeney et al., 2019). They have further been proposed to regulate capillary blood flow by virtue of their contractile properties (Hall et al., 2014; Grutzendler and Nedergaard, 2019), a concept that is currently a matter of controversy largely owing to the lack of a consensus of phenotypic definition of SMCs versus pericytes. Functionally, it has been suggested that, during functional hyperemia, pericytes respond to glutamate released signals and dilate capillaries via a prostaglandin $\mathrm{E}_{2}$-dependent pathway ( $\mathrm{Hall}$ et al., 2014). In support of a role for impaired neurovascularmediated signaling, pericyte position and function are altered by disease conditions such as stroke (Hall et al., 2014; Berthiaume et al., 2018a,b), diabetes (Rom et al., 2020) and Alzheimer's disease (AD) (Sagare et al., 2013; Nortley et al., 2019; Montagne et al., 2020), as well as disturbances in the circadian clock system (Nakazato et al., 2017) —all of which are associated with neurodegeneration.

\section{Astrocytes}

Astrocytic endfoot processes make contact with the abluminal surface of mural cells, establishing the gliovascular interface (Simard et al., 2003). Astrocytes regulate cerebral blood flow $(\mathrm{CBF})$ and contribute to the maintenance and integrity of the BBB. The multiple functions of astrocytes are reflected in the plethora of ion channels and receptors they express, as well as their active release of numerous vasoactive signals and gliotransmitters known to modulate vascular, microglial, and neuronal function (Araque et al., 2014). However, the nature of communication channels established between astrocytes, blood vessels, and neurons are unclear. The use of fluorescent dyes (Tsien, 1988, 1989) has enabled glioscientists to visualize astrocytic $\mathrm{Ca}^{2+}$ events (Cornell-Bell et al., 1990), giving rise to an upsurge in research and knowledge on astrocyte function and intercellular communication. Visualization of astrocyte $\mathrm{Ca}^{2+}$ dynamics was later improved with the development of $\mathrm{Ca}^{2+}$ 
indicators of the GCaMP series, either genetically encoded in transgenic mice or delivered via viruses (Bazargani and Attwell, 2016). The combined use of this approach with various astrocyte promoters such as Aldh111, Slc 1a3, GFAP, and GLAST has provided further knowledge on astrocyte heterogeneity in function, brain region specificity and structural dynamics.

Astrocytic $\mathrm{Ca}^{2+}$ events can be spontaneous or activitydependent. As is the case for a number of astrocyte functions, $\mathrm{Ca}^{2+}$ events are compartmentalized (Bazargani and Attwell, 2016), with large $\mathrm{Ca}^{2+}$ events occurring in the soma and smaller events occurring in processes and microdomains. Importantly, these events can have different activity patterns. How these patterns relate to function is currently under investigation, supported by emerging sophisticated quantitative analytical techniques (Wang et al., 2019a). Dynamic $\mathrm{Ca}^{2+}$ events take the form of both intracellular- and intercellular-mediated signals, the latter of which can spread in the form of waves throughout the astrocytic syncytium via gap junctions (Munoz et al., 2015; Lapato and Tiwari-Woodruff, 2018). $\mathrm{Ca}^{2+}$ events may originate within different subcompartments, including the endoplasmic reticulum and mitochondria, and discrete sites, such as inositol trisphosphate $\left(\mathrm{IP}_{3}\right)$ receptors. In addition, $\mathrm{Ca}^{2+}$ events may be initiated by activation of membranebound ion channels, receptors or transporters, such as vanilloidtype transient receptor potential channels (e.g., TRPV4) and $\mathrm{Na}^{+} / \mathrm{Ca}^{2+}$ exchangers. Notably, some of these surface proteins are functionally coupled to glutamate and GABA co-transporters (e.g., Glu/Na ${ }^{+}, \mathrm{GABA} \mathrm{Na}^{+}$cotransporters), and thereby play an essential role in regulating ambient glutamate and GABA levels (for a review, see Oheim et al., 2018; Verkhratsky et al., 2019).

Astrocyte-derived vasoactive signals include prostaglandins, epoxyeicosatrienoic acids (EETs), glutamate, $\mathrm{K}^{+}$, adenosine and ATP, among others (Girouard and Iadecola, 2006; Attwell et al., 2010). The mechanisms by which each of these signaling molecules contribute to the regulation of vascular tone appear to be vessel specific (i.e., arteriole vs. capillary) (Mishra et al., 2016).

While the participation of astrocytic $\mathrm{Ca}^{2+}$ events in NVC has been questioned, mainly due to inconsistencies in the temporal relationship between $\mathrm{Ca}^{2+}$ events and vascular responses (Nizar et al., 2013; Bonder and McCarthy, 2014), these discrepancies could reflect unintended consequences of specific experimental manipulations, such as targeting a single $\mathrm{Ca}^{2+}$ pathway $\left(\mathrm{IP}_{3}\right.$ receptor 2-knockout mice), failure to consider alternative $\mathrm{Ca}^{2+}$ sources [e.g., TRPV4 channels (Dunn et al., 2013)], anesthesia (Thrane et al., 2012; Tran and Gordon, 2015) and the arousal state of the animal (Tran et al., 2018). Technical limitations, such as the temporal and/or spatial resolution of acquired images, could also account for differences between studies. To this end, GCaMP$\mathrm{Ca}^{2+}$ indicators have shed new light on this issue (Bazargani and Attwell, 2016). Using 3D imaging, Bindocci et al. (2017) discovered that $\mathrm{Ca}^{2+}$ events occurred more rapidly in astrocytic endfeet than in the soma. Global $\mathrm{Ca}^{2+}$ events associated with mouse movement were multifocal and spread from multiple gliapil toward the core of the cell. Endfoot $\mathrm{Ca}^{2+}$ events at the gliovascular interface exhibited asynchronous patterns (Bindocci et al., 2017). Moreover, astrocytic $\mathrm{Ca}^{2+}$ transients have been shown to propagate between cell subcompartments, highlighting the diversity of responses (Grosche et al., 1999; Kanemaru et al., 2014). In an awake in vivo two-photon mouse model, Tran et al. (2018) evaluated astrocyte $\mathrm{Ca}^{2+}$ dynamics in periarterioles and peri-capillary astrocytes of the barrel cortex in response to sensory stimulation or volitional behaviors. The authors observed delayed (following dilations) astrocyte $\mathrm{Ca}^{2+}$ increases in turn dependent on the mouse's action at the time of the stimulus. Using varied stimulation approaches the authors showed that the neurovascular pathway was linked to endothelial-derived nitric oxide (Tran et al., 2018). Unraveling the functional significance of astrocytic $\mathrm{Ca}^{2+}$ activity patternsand sources (Srinivasan et al., 2015) - under both physiological and non-physiological conditions is thus of critical importance. In addition, further studies designed to link activity patterns with astrocyte population subtype are needed (Sofroniew and Vinters, 2010; Lundgaard et al., 2014).

Astrocytes are also critically involved in removing waste from the brain via the glymphatic system, a process that involves the highly specific endfoot marker and water ion channel, aquaporin 4 (AQP4). The glymphatic system operates through vessel-toglia crosstalk mediated, at least in part, by arteriole pulsatility and impaired in aged mice (Kress et al., 2014). Although this latter mechanism is not fully established, it has been proposed that these pulsations are the driving force for promoting the convection of ions, solutes and waste products across the brain interstitial space without the need to cross the BBB. There is some evidence that the absence of AQP4 at the gliovascular interface impairs clearance and transport via the glymphatic system (Iliff et al., 2012, 2013).

\section{Microglia}

Microglia are the resident immune cells of the brain (Bilbo and Stevens, 2017). These embryonic mesoderm-derived cells constantly surveil the CNS for unfamiliar antigens, pathogens, apoptotic cells, and foreign particles. Their dynamic phagocytic activity and active release of immune signals play critical roles in brain homeostasis and repair processes (Hanisch and Kettenmann, 2007). However, the neuroprotective microglial state (surveillance/execution mode) can be disturbed during pathology, causing these cells to shift toward a reactive phenotype. These reactive microglia respond with exacerbated secretion of proinflammatory mediators (Vinuesa et al., 2019) and altered phagocytotic properties (Baik et al., 2019; Zhang et al., 2020).

Whether microglia directly impact cerebrovascular function is poorly understood. It has been reported that, after a cortical stroke, microglia are recruited toward vessels, where they can phagocytize endothelial cells and thereby contribute to the increased loss of BBB integrity (Jolivel et al., 2015). Using an in vitro approach, the authors of this latter study provided evidence that fibrinogen and albumin, plasma components found in the brain parenchyma after stroke, exacerbated the secretion of microglial proinflammatory cytokines and acted as chemoattractants. However, whether phagocytosis of endothelial 
cells by microglia, a potential step in vascular repair, is part of a normal physiological process remains unknown.

To investigate this, Halder and Milner (2019) used a mouse model of mild chronic hypoxia that causes vascular leakiness and microglia clustering around vessels. Under these hypoxic conditions, pharmacological depletion of microglia increased $\mathrm{BBB}$ leakiness and caused a loss of tight junction proteins. It also led to astrocyte-vessel uncoupling, as evidenced by a decrease in the number of vessels positive for the perivascular astrocyte endfoot marker, AQP4. However, under normoxic conditions, microglia depletion did not impact vascular integrity. Thus, it is likely that coupling of these interactions is dependent on key signals released only in a pathological setting that may be absent under physiological conditions.

As alluded to above, proper operation of homeostatic mechanisms involves dynamic crosstalk among cells of the NVU, many of which have overlapping or complementary functions. These observations call for an integrated approach for addressing the functional status of the NVU and its vulnerability under disease conditions.

\section{CEREBRAL BLOOD FLOW, NEUROVASCULAR COUPLING, AND VASCULO-NEURONAL COUPLING}

High energy demands, as occur during information processing and maintenance of homeostatic processes, are sustained by redundant NVU-mediated mechanisms that ensure constitutive perfusion (Zlokovic, 2005). The driving force for CBF is cerebral perfusion pressure (CPP), defined as the difference between mean arterial pressure (MAP) and intracranial pressure (ICP). In the absence of a neuronal stimulus, CBF is relatively constant, but can be affected by changes in cardiac output, vascular resistance and altered intravascular as well as intracranial pressure gradients.

\section{Cerebral Autoregulation}

The dynamic mechanisms that regulate basal $\mathrm{CBF}$ are largely driven by the fine balance between vasodilatory and vasoconstrictive signaling pathways (Hill-Eubanks et al., 2014) and the integration of reflex autonomic pathways and local control processes, including cerebral autoregulation (Bayliss, 1902; Silverman and Petersen, 2020). The mechanisms underlying cerebral autoregulation include pressure-induced vasoconstriction (myogenic response) (Brayden et al., 2013; Cipolla et al., 2014; Pires et al., 2015) as well as metabolic and humoral signaling (Koller and Toth, 2012). The best-studied of these cellular pathways is the myogenic response, which involves activation of mechanosensitive $\mathrm{Ca}^{2+}$-permeable ion channels and a subsequent increase in $\mathrm{Ca}^{2+}$ influx into VSMCs, resulting in elevated intracellular $\mathrm{Ca}^{2+}$ and vasoconstriction (Hill et al., 2006; Cipolla, 2009; Li et al., 2014). In cerebral vessels, this process is both pressure and flow/wall shear stress dependent (Koller and Toth, 2012).

Under physiological conditions, these dynamic mechanisms operate within a MAP range of 50 to $160 \mathrm{mmHg}$ and serve to adjust the diameter of arterioles to maintain approximately constant CBF (Silverman and Petersen, 2020). However, the actual systemic arterial pressure range corresponding to this plateau phase varies (Faraco and Iadecola, 2013), with potentially significant differences reported between individuals (Tzeng et al., 2010; Liu et al., 2016; de Jong et al., 2017; Xing et al., 2017; Elting et al., 2020). Moreover, chronic diseases, such as hypertension and cerebral ischemia, can shift this autoregulatory range. Consequently, impairment of autoregulatory mechanisms that buffer blood pressure fluctuations can increase the vulnerability of the microcirculation, and hence the NVU (Iadecola, 2017). Cerebral autoregulation can be assessed by measuring changes in $\mathrm{CBF}$ in response to physiological stimuli (e.g., exercise, hypercapnia or orthostatic challenges), a response referred to as cerebrovascular reactivity (Lavi et al., 2006). Cerebrovascular reactivity is reduced in hypertension and large-artery stiffness is increased (Chirinos et al., 2019; Marmarelis et al., 2020; Silverman and Petersen, 2020), both of which contribute to cognitive decline, as we discuss below in more detail in this review article.

\section{Neurovascular Coupling}

In contrast to cerebral autoregulation, which constitutively regulates $\mathrm{CBF}, \mathrm{NVC}$ is a dynamic process characterized by robust vascular responses to vasoactive signals released upon local increases in neuronal activity. NVC mechanisms form the basis of functional hyperemic responses. The rapid redirection of blood flow driven by increases in neuronal activity ensures the targeted, uninterrupted flow of blood that is critical for brain viability and ongoing brain functions. Details of the proposed signals underlying NVC have been extensively reviewed previously (Iadecola, 2017; Hosford and Gourine, 2019).

While the sequence of events underlying communication among the various cells of the NVU is poorly understood, the current view is that capillaries and arterioles are critical for the initiation (Mishra et al., 2016; Rungta et al., 2018) and conduction/integration (Longden et al., 2017) of NVC responses. Longden et al. (2017) recently established an essential role for capillary endothelial cells in both initiation and conduction of NVC responses, showing that activation of Kir2.1 channels in capillary endothelial cells by extracellular $\mathrm{K}^{+}$, which is released during each action potential, generates a hyperpolarizing (electrical) signal that back-propagates to cause dilation of upstream penetrating arterioles and pial arteries, thereby inducing an increase in blood flow to the site of signal initiation (Tian et al., 2010; Chen et al., 2011, 2014; Longden et al., 2017; Cai et al., 2018; Rungta et al., 2018). Notably, this hyperpolarizing current travels millimeters before dissipating (Iadecola et al., 1997; Chen et al., 2011). This spatial spread of the vascular signal relative to the initiation point could lead to a mismatch between the site of elevated neural activity and the location of vascular responses, highlighting the potential role of additional mechanisms at different levels of the vascular network in decoding functional hemodynamics (Jukovskaya et al., 2011; O'Herron et al., 2016). Indeed, using two-photon imaging, O'Herron et al. (2016) demonstrated that neuronal activity was more strongly coupled to the responses of nearby parenchymal arterioles than with the responses of upstream pial vessels. 
Interestingly, it is conceivable that the propagating dilatory signal not only moves upstream to the surface but also travels from the surface back down into penetrating branches. Though this aspect of vascular signaling has received little attention, low-resolution vascular imaging suggests that it readily occurs (Chen et al., 2011), providing a possible explanation for the residual mismatch between neural activity and nearby vascular responses.

There is also evidence supporting pericytes and VSMCs as first responders (Hall et al., 2014; Mishra et al., 2016). Using brain slices, Mishra et al. (2016) showed that neuronal activity evokes increases in astrocytic $\mathrm{Ca}^{2+}$ (via activation of the ionotropic ATP receptor, $\mathrm{P}_{2} \mathrm{X}_{1}$ ) that stimulate the synthesis of prostaglandin E2 $\left(\mathrm{PGE}_{2}\right)$ and its release from astrocytic endfeet, resulting in capillary dilation through activation of $\mathrm{EP}_{4}$ receptors on pericytes. However, in a follow-up study using two-photon in vivo imaging, Rungta et al. (2018) assessed changes in intracellular $\mathrm{Ca}^{2+}$ in pericytes and VSMCs in relation to distinct capillary and arteriole $\mathrm{Ca}^{2+}$ levels induced by olfactory neuronal activation (Rungta et al., 2018). In this study, an odor stimulus was followed by fast, synchronized decreases in $\mathrm{Ca}^{2+}$ in arterioles and first-order capillaries (less than $\sim 50 \mu \mathrm{m}$ from the arteriole) (Rungta et al., 2018). It was determined that pericytes near the activated synaptic site responded with a delayed drop in $\mathrm{Ca}^{2+}$ as opposed to mural cells upstream. Thus, the authors proposed the drop in $\mathrm{Ca}^{2+}$ was likely generated from heterocellular electrical coupling between endothelial and mural cells via a retrograde hyperpolarization and transfer of current via myoendothelial junctions (Iadecola et al., 1997; Chen et al., 2014; Longden et al., 2017; Harraz et al., 2020). Collectively, these studies support capillary endothelial cells as the initiators of the NVC response.

Another mechanism shown to contribute to the initiation of functional hyperemic responses involves changes in the velocity of red blood cells (Wei et al., 2016), a process that is independent of NVU vasoactive signals (Grutzendler and Nedergaard, 2019). Wei et al. (2016) provided evidence that the transient decrease in tissue $\mathrm{O}_{2}$ tension resulting from neuronal-evoked increases in metabolic activity (Devor et al., 2011) increases red blood cell deformability and velocity in capillaries. The authors proposed that $\mathrm{O}_{2}$ release-induced displacement of ankyrin from band 3 weakens spectrin-actin cytoskeleton interactions (Stefanovic et al., 2013; Zhou et al., 2019), thereby increasing erythrocytes deformability (Wei et al., 2016), a phenomenon later confirmed using both ex vivo (microfluidics) and in vivo (two-photon imaging) approaches (Zhou et al., 2019).

Understanding the cellular mechanisms underlying efficient NVC is crucial for the development of therapeutic approaches targeting potential mismatches in metabolic demand and supply as occurs in disease conditions, making this an active area of investigation.

\section{Vasculo-Neuronal Coupling}

While NVC mechanisms act to communicate information from neurons to the vasculature, communication in the opposite direction has also been proposed. At the cellular level, this modality of communication is referred to as VNC. This concept, encapsulated in the hemo-neural hypothesis, posits that hemodynamic signals modify glial and neuronal function to maintain cerebral homeostasis and contribute to information processing in the brain (Moore and Cao, 2008; Cao et al., 2009). In support of vascular-to-neuron signaling in the brain, Waki et al. (2006) showed that inhibition of eNOS in the nucleus tractus solitarii (NTS) decreased arterial pressure in the spontaneously hypertensive rat (SHR) model, indicating a role for endothelialderived NO in the NTS in modulating cardiac baroreceptor reflex gain and arterial pressure. Using acute rat brain slices and a mechanical stimulation paradigm that targets endothelial cells, Kozlov further demonstrated that VSMCs and astrocyte endfeet generate inhibitory, slow, outward currents in mitral cells of the olfactory bulb that are mediated by GABA released from astrocytes (Kozlov et al., 2006). Thesen et al. (2012) provided indirect experimental evidence in favor of the hemo-neuronal hypothesis in humans, demonstrating changes in neuronal activity in response to hypercapnia $\left(5 \% \mathrm{CO}_{2}\right)$. Specifically, they showed that hypercapnia, a prominent inducer of vascular dilation, decreased the magnetoencephalogram response to auditory and visual tasks (Thesen et al., 2012), reducing both evoked and spontaneous spectral power indicative of neuronal activity. These data support a link between resting perfusion status and neuronal activity and highlight the importance of considering this linkage in assessments of activity-dependent changes in blood flow. However, because $\mathrm{pH}$ acidification can independently affect blood vessels and neuronal activity, the concept will require further refinement.

Using a brain slice model, our group showed that arteriole constriction is associated with inhibition of neuronal firing, whereas dilation is linked to activation of neuronal firing. A detailed investigation of the constriction-dependent pathway revealed the involvement of TRPV4 channel-mediated, $\mathrm{Ca}^{2+}$ dependent events in astrocytes (Kim et al., 2015, 2016). While the mechanisms are incompletely understood, the constrictionevoked inhibition in neuronal activity was unaffected by blockers of $\mathrm{NO}, \mathrm{GABA}_{A}$ receptors or glutamate receptors. On the other hand, the response was significantly blunted by an adenosine A1 receptor blocker, and to some extent by blockade of $\mathrm{GABA}_{B}$ receptors (Kim et al., 2016).

Both arteriole constriction and dilation induce changes in astrocytic $\mathrm{Ca}^{2+}$, independent of neuronal activity (Kim et al., 2015; Rosenegger et al., 2015). One possible mechanism for this is that changes in vessel diameter trigger activation of mechanosensitive ion channels, or receptors, at the NVU. The resulting increase in astrocytic $\mathrm{Ca}^{2+}$ could then engage downstream pathways, leading to changes in neuronal activity. While evidence supports mechanosensitivity in astrocytes, how this might influence neurovascular interactions is unclear, as these processes remain largely unexplored. Mechanostimulusinduced changes in astrocytic $\mathrm{Ca}^{2+}$ could be attributable to a number of different ion channels, including P2 $\times 7$ (Beckel et al., 2014; Albalawi et al., 2017), TRPV4 (Ryskamp et al., 2011; Dunn et al., 2013; Choi et al., 2015), Piezo1 (Choi et al., 2015; Velasco-Estevez et al., 2020), and pannexin1 (Minelli et al., 2007; Suadicani et al., 2012). Evidence also supports the idea that mechanical stimulation causes the release of adenosine in the brain. Further studies addressing the implications of mechanical 
distortion-driven signaling at the NVU are clearly warranted. A good starting point would be the gliovascular interface, where specialized ion channels reside and where arteriole pulsation may play an important role in conveying mechanoregulation-driven communication (Ross et al., 2014; Nguyen and Venton, 2015; Wang and Venton, 2019; Wei et al., 2019).

We proposed VNC as a constitutively active mechanism involved in the modulation of resting neuronal activity that contributes to matching perfusion levels with energy demand. In this view, VNC would serve to safeguard neurons in cases where perfusion was compromised. A further prediction is that, in the healthy brain, VNC is overridden during increases in neuronal activity, such as those evoked during NVC. If VNC is linked to mechanosensitivity at the NVU, its operation could be further affected by intracranial and intravascular pressure gradients, which have recognized relevance in stroke and traumatic brain injury. The potential intersection of such pressure gradients with VNC could also be important in the context of hypertension, vascular stiffness and small vessel disease, an issue that warrants further investigation.

\section{VASCULAR RISK FACTORS AND THE NVU}

\section{Hypertension}

Genetic, epigenetic, and lifestyle factors contribute to hypertension (Padmanabhan et al., 2015). Also, the prevalence and severity of hypertension increase with age. From age 20-85 years of age, the lifetime risk of hypertension has been estimated at 69.3-86.1\% depending on sex and race (Virani et al., 2020). With the world's older population rising, the number of older adults with hypertension is expected to grow by $20 \%$ by 2050 (Benetos et al., 2019; Volpe et al., 2019). Yet, many older adults remain untreated or the management of their hypertension challenging to address. In the brain, chronically increased arterial pressure leads to lacunar infarcts, white matter hyperintensities, and cerebral microbleeds (Joutel and Faraci, 2014). Hypertension also results in blood vessel remodeling, increased cerebrovascular resistance, cerebral hypoperfusion and impaired NVC (Girouard and Iadecola, 2006; Calcinaghi et al., 2013; Alosco et al., 2014; Hu et al., 2017), making it a risk factor for small vessel disease (Joutel and Chabriat, 2017) and a leading contributor to stroke. Importantly, untreated mid-life hypertension is a modifiable risk factor for the early development of dementia (Mogi, 2019).

In response to elevated intravascular pressure, arteries undergo various remodeling processes, including hypertrophic remodeling, hypotrophic remodeling, inward remodeling, and arterial stiffening (Baumbach and Ghoneim, 1993; Intengan and Schiffrin, 2001; Pires et al., 2013). The most-studied cerebral vascular beds in hypertension include branches of the internal carotids and vertebral arteries, which perfuse the brain and cerebellum/brainstem, respectively. Hypertension differentially affects these two branches of the circulation, with vertebral artery remodeling preceding that of the common carotids (Dickinson and Thomason, 1959). These anatomical and functional observations support the idea that brain areas that are home to cardiovascular-related control centers may be the first targets of the disease. Thus, hypertension leads to regional variations in CBF (i.e., hypoperfusion) and, consequently, changes in neuronal output function.

Importantly, hypertension also alters the normal function of parenchymal arterioles-the ultimate effector of parenchymal perfusion (Iddings et al., 2015; Pires et al., 2015; Sweet et al., 2015; Diaz et al., 2019). Parenchymal arterioles from SHRs and their stroke-prone SHRSP derivatives exhibit increased tone (Iddings et al., 2015; Pires et al., 2015; Sweet et al., 2015), increased wall thickness and passive distensibility (Sweet et al., 2015), decreased resting lumen diameter, and inward remodeling (Pires et al., 2015). Our group also reported increases in parenchymal arteriole tone in ex vivo brain slice preparations from mice infused with Ang II $(600 \mathrm{ng} / \mathrm{kg} / \mathrm{min})$ for 28 days (Diaz et al., 2019). In addition, DOCA-salt-induced hypertension has been shown to impair endothelium-dependent dilation via dysfunctional cyclooxygenase (COX) and NO signaling (Matin et al., 2016).

It has previously been shown that the reduced cerebral perfusion and pathological parenchymal arteriole remodeling are reversed by endothelial cell-specific knockout of the mineralocorticoid receptor (MR) or $\mathrm{MR}$ antagonism in mice (Diaz-Otero et al., 2017). Diaz-Otero and colleagues showed that MR activation impairs TRPV4 channel-mediated dilation of parenchymal arterioles in a mouse model of angiotensin II (Ang II)-induced hypertension. The authors also reported that, in the hypertensive group, MR blockade rescued myogenic tone, reduced microglia density, and improved cognitive function (Diaz-Otero et al., 2018). The authors then evaluated the role of TRPV4 channels in vessel dysfunction using a TRPV4-knockout rat model [WKY-Trpv4(em4Mcwi)], reporting reduced cerebral perfusion with no changes in parenchymal arteriole structure or myogenic tone. However, these rats did show impaired endothelium-dependent dilation and cognitive function in association with gliosis (Diaz-Otero et al., 2019). It has further been shown that relaxation of VSMCs is diminished in mesenteric arteries of SHR and SHRSP models; this effect was attributed to a decrease in the generation of the endothelium-dependent hyperpolarizing factor, a process that likely depends on TRPV4 and SK channel signaling (Seki et al., 2017). TRPV4 channel activity was further evaluated by Tajada et al. (2017) using super-resolution imaging. These authors showed that TRPV4 channel activity was dependent on the protein kinase $\mathrm{C} \alpha$ $(\mathrm{PKC} \alpha)$ membrane-anchoring protein AKP150, and further demonstrated that Ang II produced a decay in TRPV4 activation that was negatively correlated with the distance between TRPV4 channels and AKAP.

Yamasaki et al. (2020) showed that angiotensin II type 1 receptors $\left(\mathrm{AT}_{1} \mathrm{Rs}\right)$ were differentially expressed between pial arteries and parenchymal arterioles of the cerebral microvasculature. These authors reported that, whereas mRNA expression levels of the angiotensin II receptor subtypes $\mathrm{AT}_{1} \mathrm{R}_{a}$ and $\mathrm{AT}_{1} \mathrm{R}_{b}$ were comparable in parenchymal arterioles, expression levels of $\mathrm{AT}_{1} \mathrm{R}_{b}$ were $\sim 11$-fold higher than those of $\mathrm{AT}_{1} \mathrm{R}_{a}$ in pial arteries. These differences in expression suggest 
differences in the sensitivity of these vessels to Ang II (Yamasaki et al., 2020). However, how expression of these receptors is altered throughout the different stages of hypertension was not evaluated in this study. An important functional observation was that $\mathrm{AT}_{1} \mathrm{R}$ activation in parenchymal arterioles is important for the initiation, but not the maintenance, of the myogenic response. The authors suggested that a $G$ protein-coupled receptor (GPCRs), such as $\mathrm{AT}_{1} \mathrm{R}$, acts as the main intravascular pressure sensor, providing a molecular pathway critical for cerebral autoregulation (Yamasaki et al., 2020).

Hypertension also targets cerebral capillaries. Hypertension impairs endothelial function and BBB integrity (Santisteban and Iadecola, 2018). Both animal models of hypertension (Tarantini et al., 2016) and hypertensive patients (Bosch et al., 2017) show capillary rarefaction. Loss of capillaries is associated with ischemia resulting in inadequate metabolic supply to neurons and glial cells contributing to elevated oxidative stress and inflammation and an overall toxic environment. There's also a synergistic effect of hypertension with both aging and $\mathrm{AD}$ on microvascular damage (Toth et al., 2013; Tarantini et al., 2016). Accompanied by a decrease in the number of upstream arterioles (De Silva and Faraci, 2020), hypertension contributes to an overall reduction in cerebral perfusion. Because endothelial dysfunction is a hallmark of hypertension, it would be important to address whether hypertension alters the electrical conduction of endothelial cells and, thus, the ability of capillaries to initiate the propagation of the upstream vasodilation, characteristic of the NVC response (Chen et al., 2014; Longden et al., 2017). A critical factor associated with the retrograde upstream propagation of the hyperpolarizing current is phosphatidylinositol 4,5-bisphosphate $\left(\mathrm{PIP}_{2}\right)$. Gq-protein-coupled receptors, targets of numerous NVC mediators, evokes PLC-mediated hydrolysis of $\mathrm{PIP}_{2}$ into $\mathrm{IP}_{3}$ and DAG, which in turn modulate ion channels involved in the regulation of vascular tone (Harraz et al., 2018b) including Kir2.1 and TRPV4 ion channels (Harraz et al., 2018a,b; Moshkforoush et al., 2020). Given that ischemia alters oxidative phosphorylation and ATP synthesis, the impact of $\mathrm{PIP}_{2}$-mediated ion channel regulation on the vasculature is of importance (Harraz et al., 2018b). Future work on this research area will help elucidate the effect of aging, as well as hypertensioninduced capillary dysfunction, has on the mechanisms underlying neurovascular uncoupling.

Collectively, these studies support the concept that parenchymal arterioles and capillaries are a target of hypertension, which manifests as increased tone and endothelial dysfunction, and is accompanied with gliosis (Iddings et al., 2015; Pires et al., 2015; Sweet et al., 2015; Diaz et al., 2019).

\section{Hypoperfusion and Oxidative Stress in Hypertension}

Reduced CBF is correlated with accelerated cognitive decline and ultimately leads to dementia (Hakim, 2019). Using MRI analyses and clinical history data for 59 patients who suffered a transient ischemic attack, Wang and colleagues reported that $67.8 \%$ of such patients presented a history of hypertension.
They also observed a strong correlation between hypertension and perfusion abnormalities that was independent of the ischemic attack (Wang et al., 2019b). Hypertension, together with hypoperfusion, can result in significant dysregulation of cerebral vessels, increasing vascular resistance and exacerbating myogenic constriction (Iddings et al., 2015). As part of a consequent, and presumably protective, response mechanism, hypertension shifts the cerebral autoregulation curve to the right (Koller and Toth, 2012), an adaptation that also increases the risk for hypoperfusion when systemic blood pressure decreases (Faraco and Iadecola, 2013; Toth et al., 2017). However, these protective adaptations may be lost in the aged brain. Using an Ang II-infused model of hypertension in mice, Toth et al. (2013) investigated the effects of increased pressure-induced tone in middle cerebral arteries of 3-monthold mice. They found that the mechanism governing increased tone involved upregulation of the vasoconstrictor pathway driven by 20-HETE (20-hydroxy-5,8,11,14-eicosatetraenoic acid) and the canonical transient receptor potential cation channel member, TRPC6. However, in aged mice (24 months), this mechanism was impaired, increasing the vulnerability of the cerebral microcirculation to blood pressure fluctuations (Toth et al., 2013).

Chan et al. (2019) recently provided support for a role for endothelial TRPV4 channels in the regulation of parenchymal arteriole tone and vascular remodeling during hypoperfusion. In these studies, wild-type and TRPV4-knockout (KO) mice were subjected to unilateral common carotid artery occlusion (UCCAo) for 28 days. In wild-type mice, UCCAo caused a decrease in active tone and increased passive inner diameters (Chan et al., 2019). The decreased tone was dependent on TRPV4 channel function but not the outward remodeling. These effects of UCCAo on myogenic tone did not involve NO signaling. The same group showed decreased myogenic tone in control WKY rats subjected to UCCAo, an effect that was not observed in SHRSP model animals (Sweet et al., 2015). Together, these data suggest that ischemia, as well as hypertension, result in the activation of distinct compensatory processes. While ischemiarelated signaling is geared toward maintaining vessels open and sustaining CBF, hypertension-induced increases in vascular tone serve to prevent hyperperfusion-induced microvascular damage. In hypertension, remodeling and increased vascular reactivity may lead to hypoperfusion and the onset of cerebral ischemia.

Reactive oxygen species (ROS), which are elevated in hypertension (Montezano et al., 2015), are involved in vascular inflammation, fibrosis and arterial remodeling (Tanaka and Laurindo, 2017), and thus contribute to vascular dysfunction (Lopes et al., 2015). Using a transcriptomic approach, Walas et al. (2019) presented evidence that, prior to the onset of hypertension, cerebral arteries from the posterior circulation of 5-week-old SHRs exhibit elevated expression of genes related to remodeling, oxidative stress, and inflammatory pathways, notably including a $40 \%$ increase in genes related to fibrosis (e.g., TGF $\beta$ ). Among the changes noted during this prehypertension period were dysregulation of pro-fibrotic pathways (e.g., upregulation of enolase-1) and inflammatory pathways 
(e.g., inhibition of interferons, TLR3 and STAT1) as well as altered mitochondrial function. The authors proposed that these changes support previously reported immune cell infiltration (Waki et al., 2007, 2013; Xu et al., 2012; Marvar et al., 2016). The resulting vessel remodeling alters vascular function, increasing cerebrovascular resistance and decreasing CBF, both of which contribute to increased sympathetic nerve activity via the Cushing mechanism, as recently reviewed (McBryde et al., 2017). The onset of hypertension was thus regarded as a secondary insult that worsened vessel fibrosis and stiffening and also caused endothelial dysfunction. These results obtained using the SHR model suggest that early therapeutic approaches targeting immune system dysfunction may prevent vascular dysfunction associated with hypertension.

Increased oxidative stress and resulting endothelial dysfunction are also associated with decreased CBF and increased BBB permeability (Iadecola, 2013). Moreover, hypertension is correlated with the size and prevalence of microbleeds (Vernooij et al., 2008; Shams et al., 2015) - a marker of vessel damage-and BBB breakdown. Increased ROS levels promote increases in intracellular astrocytic $\mathrm{Ca}^{2+}$, which has been linked to the ability of astrocytes to sense hypoxia (Angelova and Abramov, 2016). In the context of exacerbated ROS levels in disease, this mechanism may contribute to the pathogenesis of neurodegenerative disorders.

In mice, Ang II-dependent hypertension impaired NVCevoked increases in CBF and endothelial-mediated vasodilation (Capone et al., 2012; Johnson et al., 2013). Ang II-induced hypertension is associated with increased activation of NADPH oxidase and enhanced ROS production (Kazama et al., 2004; Capone et al., 2011). Iulita et al. (2019) provided evidence that in a murine Ang II-dependent model of hypertension (1000 $\mathrm{ng} / \mathrm{kg} / \mathrm{min})$, the adoptive transfer of Treg cells prevented neurovascular uncoupling and endothelial dysfunction. Neuroprotective effects were linked to IL-10 signaling and abolished in IL-10 deficient mice. Notably, the adoptive transfer of Tregs reduced Ang II-induced systemic inflammation, microgliosis and superoxide radicals (Iulita et al., 2019). Faraco et al. (2016), investigated the contribution of perivascular macrophages (PVMs), resident brain macrophages with the capacity to generate ROS, to hypertension-induced neurovascular and cognitive dysfunction. Low Ang II doses was shown to increase BBB permeability and Ang II access into perivascular spaces. The subsequent PVM activation, via AT1R and the NADPH oxidase subunit NOX2, contributed to ROS production (Faraco et al., 2016). The authors further demonstrated that in $\mathrm{BPH} / 2 \mathrm{~J}$ mice, PVM depletion improved cognitive impairments, providing an important link between hypertension, PVM/inflammation, and cognitive dysfunction (Faraco et al., 2016). The same group recently demonstrated that Ang II-induced hypertension in mice leads to tight junction remodeling and increased $\mathrm{BBB}$ permeability, an effect more pronounced in arterioles than capillaries (Santisteban et al., 2020). The authors proposed a mechanism by which circulating Ang II leads to AT1a receptor activation in endothelial cells and downregulation of $M f s d 2 a$. The resulting increased vesicular transport of Ang II into the perivascular space would then lead to
AT1R and NOX2 activation in PVM, increasing BBB disruption (Santisteban et al., 2020).

\section{Inflammation, Aberrant Astrocytic $\mathbf{C a}^{2+}$ and Disease}

While astrocytes are known for their trophic support, these cells also participate in proinflammatory processes (Pomilio et al., 2016; Verkhratsky and Nedergaard, 2018). Alteration in glial function and morphology (i.e., astrogliosis) is associated with disease states, vasodilator dysfunction of cerebral parenchymal arterioles (Bagi et al., 2018) and cognitive dysfunction (Verkhratsky and Nedergaard, 2018). Hypertension, regarded as a chronic inflammatory state (De Miguel et al., 2015; Rodriguez-Iturbe et al., 2017), impairs one of the first barriers of brain protection, the BBB (Katsi et al., 2020; Santisteban et al., 2020). BBB dysfunction facilitates the infiltration of plasma components to the brain and the production of proinflammatory signals that lead to microglia and astrocyte activation. These inflammatory processes impair the glial trophic support of both the vasculature and neurons (Iadecola, 2013). The extensive coverage of astrocytic processes along the cerebral microcirculation could be regarded as the next in line protective barrier (Sofroniew, 2015). However, how endothelial dysfunction alters the functional properties of astrocytes remains poorly understood. We speculate that the progressive impairment of the cerebral microcirculation, accompanied by the release of inflammatory markers, contributes to a shift in astrocyte phenotype from protective to inflammatory. Consequently, neuroinflammation directed by glial cells may contribute to hypertension-related cognitive impairment.

Efforts have been made to delineate astrocyte functional phenotypes based on the expression of specific markers, as previously reviewed (Miller, 2018). To this point, however, molecular profiling strategies (e.g., single-cell transcriptomics), have not been able to fully determine astrocyte functional status. Despite transcriptomic comparisons between astrocytes positive for GFAP, ALDH1L1, GLT1 or HEPACAM, the co-expression of markers in the majority of astrocytes has limited the ability to identify astrocyte subpopulations (Lovatt et al., 2007; Yang et al., 2011; Zhang et al., 2016).

To date, two major astrocyte phenotypes have been described based on their susceptibility to signals from microglia. A1 astrocytes, analogous to the controversial M1 microglia subtype, develop a proinflammatory phenotype that cannot support synapse formation or phagocytosis. The A1 phenotype is primarily driven by interleukin (IL)-1 $\alpha$, tumor necrosis factor (TNF)- $\alpha$, and C1q (complement component 1 , subcomponent q) (Liddelow et al., 2017). On the other hand, trophic or protective astrocytes, referred to as A2 astrocytes, represent the normally functioning astrocyte subtype. The A2 astrocyte phenotype is also linked to the promotion of neuronal survival following ischemia (Liddelow et al., 2017; Clarke et al., 2018). Importantly, whether astrocytes can reversibly switch from one phenotype to the other is presently unknown.

Given limited knowledge on the factors leading to astrocytes functional transition from supportive to proinflammatory, 
alternative approaches, including incorporation of an assessment of $\mathrm{Ca}^{2+}$ dynamics, are pivotal for interpreting astrocyte function and population subtype. Increasing evidence pointing to aberrant astrocytic $\mathrm{Ca}^{2+}$ as an early indicator of disease state and severity strengthens the importance of decoding astrocyte communication at the NVU for optimal brain function (Shigetomi et al., 2019).

Models of cerebrovascular pathology such as stroke (Morrison and Filosa, 2016; Morrison and Filosa, 2019) and AD, show increases in astrocyte $\mathrm{Ca}^{2+}$ events (Delekate et al., 2014). Less understood, however, is the impact of hypertension on astrocyte $\mathrm{Ca}^{2+}$ dynamics and function. Ohara and Nabika (2016) identified a point mutation in stromal interaction molecule-1 (Stim1) in the SHRSP model, and further showed that truncated STIM1 impaired $\mathrm{Ca}^{2+}$ signaling regulated by store-operated $\mathrm{Ca}^{2+}$-entry in cultured astrocytes. Diaz et al. (2019) showed augmented spontaneous and myogenic-evoked $\mathrm{Ca}^{2+}$ events in microdomains of cortical astrocytes from Ang II-induced hypertensive mice, events that were accompanied by increased TRPV4 channel function. Although it is not entirely clear how this contributes to pathogenesis, the authors hypothesized that sustained intracellular $\mathrm{Ca}^{2+}$ elevations in astrocytes could trigger or facilitate the transition of these cells to a proinflammatory state. In support of this, exacerbated TRPV4 channel activation has been linked to the release of proinflammatory signals (Krizaj et al., 2014) that may, in turn, initiate astrocyte-microglia interactions (e.g., ATP, DAMPs), establishing a feed-forward response that aggravates neuroinflammation at the NVU.

In $\mathrm{AD}$, astrocytes in the vicinity of amyloid plaques exhibit abnormally elevated $\mathrm{Ca}^{2+}$ levels (Shigetomi et al., 2019). Astrocytes in acute brain slices also respond to exposure to $\mathrm{A} \beta$ oligomers with an increase in intracellular $\mathrm{Ca}^{2+}$ (Tyurikova et al., 2018). Similar findings have been reported in stroke, were astrocytes in proximity to damaged tissue show increased $\mathrm{Ca}^{2+}$ (Shigetomi et al., 2019). Notably, suppression of aberrant astrocytic $\mathrm{Ca}^{2+}$ signals in the context of stroke reduces cell and tissue damage (Ding et al., 2009), indicating that astrocyte $\mathrm{Ca}^{2+}$ overload can lead to pathology. Further studies are needed to uncover mechanistic details of altered astrocytic $\mathrm{Ca}^{2+}$ signaling in AD models.

\section{Vascular Stiffness}

There are several human studies and observations indicating that hypertension and aging exert synergistic effects on cognitive decline (Csiszar et al., 2013). In fact, hypertension may prompt the early onset of mechanisms underlying accelerated aging. Both hypertension and aging increase vascular stiffness. In healthy elastic arteries (thoracic aorta and common carotid artery), the compliance of these vessels dampens pressure and flow fluctuations, thereby allowing delivery of a steady flow of blood to the more vulnerable microcirculation (Chirinos et al., 2019). Sustained mechanical stress causes arteries to lose their distensibility, leading to increased stiffness (Avolio et al., 2018; Mitchell, 2018). Thus, both age and hypertension result in a reduction in pressure-buffering capacity upstream from the cerebral microcirculation. As a consequence, the amplitude of pulsations transmitted to the carotids is increased
(Mitchell et al., 2011). At the microcirculation level, hypertension contributes to small vessel disease (Faraci, 2018). Moreover, hypertension results in increase wall stiffness of larger vessels (i.e., posterior cerebral artery) and increased wall stress and wall thickness of parenchymal arteriole (Diaz-Otero et al., 2016). While few have addressed the importance of understanding the relationship between the macro- and micro-vasculature, these questions are emerging (Climie et al., 2019) and constitute new paradigms toward the development of new therapeutic targets addressing the impact of cardiovascular disease on cognitive function.

Arterial stiffness is a predictor of cardiovascular risk. In clinical practice, the gold standard for measurements of regional arterial stiffness is pulse wave velocity (PWV) (Negoita et al., 2018). The PWV, often measured from the carotid to the femoral artery, is defined as the distance traveled by the pulse wave from the carotid point to the femoral point $(\Delta \mathrm{L})$ divided by the time of travel $(\Delta \mathrm{T})$ or, $\mathrm{PWV}=\Delta \mathrm{L} / \Delta \mathrm{T}$. In the aging population, increased pulse pressure is also linked to hypertension. To this end, measurements of wave intensity and wave separation analysis (Fok et al., 2014; Su et al., 2017) allow pressures to be separated into the push forward (from the ventricle against the arterial tree) and backward (from arterial tree against the ventricle) components (Fok et al., 2014). Thus, different components of the pressure wave can provide information related to the pressures generated from the ventricle and the arterial tree.

Arteries from hypertensive patients exhibit increased stiffness and a loss of distensibility, which increases their susceptibility to pulse pressure-mediated damage (Lacolley et al., 2018). A previous study evaluated the relationship between small vessel disease and aortic PWV in 167 hypertensive patients without a history of vascular or cerebrovascular disease (Henskens et al., 2008), demonstrating a positive correlation between PWV and white matter hyperintensities and the presence of silent lacunar infarcts. This correlation held even in younger patients $(<50$ years old) and was independent of vascular risk factors (i.e., MAP and age). Increasing the duration of the momentum of the pulse pressure increased the risk for tissue damage (Henskens et al., 2008).

A study that followed $>3000$ patients evaluated the relationship between downstream small vessel damage and cognitive decline. Using forward compression wave intensity (FCWI), which measures the intensity of pulsatile waves traveling via the carotids toward the brain, it was concluded that elevated carotid artery FCWI was correlated with earlier cognitive decline, independently of other cardiovascular factors (Chiesa et al., 2019). In this study, participants were examined for changes in memory, executive function, and fluency over 13 years. Those with a higher FCWI in the carotid artery showed a 50\% greater chance of developing cognitive dysfunction, even after adjusting for several factors, including education. In a cross-sectional study that included 668 females and males between 69 and 93 years of age, Mitchell et al. (2011) reported that higher carotid pulse pressure and carotid flow pulse amplitude were correlated with reduced cognitive function, assessed by tests of memory, executive function, and processing speed (Mitchell et al., 2011). 
An increase in PWV was shown to contribute to cognitive dysfunction through its negative impacts on white and gray matter volumes and its positive correlation with lacunar infarcts and white matter hyperintensities.

Increased vascular stiffness may result from increases in blood pressure variability (BPV) (Rothwell, 2010; Schillaci et al., 2012), defined as blood pressure fluctuations over time, where time can be measured in seconds to years (short-term, $\leq 24 \mathrm{~h}$; mid-term, days/weeks; long-term, years) (Stevens et al., 2016, 2019). BPV is emerging as an independent predictor of cardiovascular risk and dementia (Merkler and Iadecola, 2017; Oishi et al., 2017). While the mechanisms underlying BPV are still unclear, augmented blood pressure fluctuations may be the result of reduced ability to buffer normal changes due to impaired vascular function (e.g., increased vascular stiffness), impaired baroreflex sensitivity and/or sympathetic nerve responses (Schillaci et al., 2012). BPV contributes to cardiovascular complications in hypertension, and antihypertensive agents that control it help prevent the development of cardiovascular events (Rothwell et al., 2010; Parati et al., 2012). A meta-analysis that included data from 27 articles and more than 12,000 individuals determined that greater short-term (24 h) BPV in humans was correlated with subcortical infarct, lacunae, white matter hyperintensities, cerebral microbleeds and/or enlarged perivascular spaces (Tully et al., 2020). Further supporting the adverse effect of increased BPV on neurovascular function, Oishi et al. (2017), provided evidence that BPV, is an independent risk factor in the development of $\mathrm{AD}$ and vascular cognitive impairment/dementia.

Multiple cellular and extracellular matrix mechanisms contribute to vascular stiffness, including elastin fragmentation, collagen deposition, advanced glycation endproduct (AGE)mediated collagen and elastin cross-linking, impaired VSMC function and calcification, endothelial dysfunction, inflammation and oxidative stress, among others (Chirinos et al., 2019). While advances have been made in elucidating the impact of the reninangiotensin system (RAS), especially Ang II (Forrester et al., 2018), on vascular fibrosis and arterial stiffness, the underlying cellular and molecular mechanisms remain elusive. Ang II in hypertension and arteriosclerosis is linked to inflammation and oxidative stress (Rodriguez-Iturbe et al., 2017). In VSMCs, elevated intracellular $\mathrm{Ca}^{2+}$, increased actin-myosin cross-bridge formation, cytoskeleton rearrangement, ROS, inflammationrelated non-coding RNAs, as well as $\mathrm{Ca}^{2+}$-independent mechanisms involving RhoA-Rho kinase, protein kinase $\mathrm{C}$ and mitogen-activated protein kinase signaling lead to increased vasoconstriction and arterial remodeling, as recently reviewed by Touyz et al. (2018). Using a mouse model of arterial stiffness induced by administration of $\mathrm{CaCl}_{2}$ into the adventitia of the carotid artery, Sadekova et al. (2018) showed increased microglia and astrocyte reactivity in the hippocampus and frontal cortex. In this case, the observed gliosis was associated with NADPH-generated oxidative stress (Sadekova et al., 2018).

Taken together, while numerous human studies and observations found strong correlations between arterial stiffening and impaired cerebrovascular function in hypertension and cognitive decline, the apparent lack of direct mechanistic links and experimental evidence for well-defined molecular targets prevents therapeutic progress.

\section{VASCULAR CONTRIBUTORS TO COGNITIVE IMPAIRMENT AND DEMENTIA}

The prevalence of hypertension, a modifiable risk factor for cardiovascular disease, increases with age. Importantly, in hypertensive patients, aging accelerates cognitive decline (Livingston et al., 2017). Thus, understanding the cellular mechanisms underlying hypertension- and aging-induced cognitive decline is pivotal for the development of therapeutic strategies in the prevention of vascular-related dementia.

The most common form of dementia is $\mathrm{AD}$, a multifactorial neurodegenerative disease (Pomilio et al., 2020). Early presentations of $\mathrm{AD}$ include neurovascular dysfunction and microvasculature alterations (Sagare et al., 2013). Iturria-Medina et al. (2016) analyzed 7,700 brain images and dozens of plasma and cerebrospinal fluid biomarkers from the Alzheimer's Disease Neuroimaging Initiative (ADNI), looking for abnormalities related to vascular, amyloid, metabolic, functional, and structural changes. They found that vascular dysfunction was an early pathological event. Importantly, cognitive decline was noticeable from the initial stages of late-onset $\mathrm{AD}$ and was associated with vascular alterations.

Mouse models of familial AD exhibit differences depending on the specific mutations and transgenes they carry. However, many present vascular alterations (Iadecola, 2017), including altered cerebral perfusion (Hebert et al., 2013; Guo et al., 2019), impaired NVC (Badhwar et al., 2013; Lu et al., 2019), capillary endothelial degeneration, thickening (Zlokovic, 2005), and loss of pericytes and BBB integrity (Sagare et al., 2013; Montagne et al., 2020), before behavioral changes and deposition of amyloid plaques. As in humans, these observations support the notion that vascular dysfunction is an essential factor in the onset of cognitive decline.

Increased blood pressure in mid-life is positively associated with cognitive decline or AD late in life (Skoog et al., 1996). A recent report of a clinical trial with a 6-year follow-up concluded that controlling blood pressure at a target level less than $140 \mathrm{mmHg}$ decreased the incidence of mild cognitive impairment and lowered the risk of dementia (Sprint Mind Investigators for the Sprint Research Group, Williamson et al., 2019). Given the availability of potentially beneficial therapeutics and the lack of successful interventions for AD (Edwards Iii et al., 2019), antihypertensive drugs have been explored as AD treatments. A retrospective cohort analysis of patients taking antihypertensive RAS-acting medicines, including angiotensinconverting enzyme inhibitors (ACEIs) and Ang II receptor blockers (ARBs), reported that AD incidence was lower in women (both Caucasian and African American) and Caucasian men taking ARBs compared with their counterparts not taking RASacting drugs (Barthold et al., 2018). Furthermore, a meta-analysis found that controlling blood pressure with antihypertensive drugs in and of itself may have positive outcomes for cognitive function (Ding et al., 2020). 




Targeting the RAS using Ang II receptor blockers has proven beneficial for cognition in both human patients and animal models. AD mice (J20 model) treated with losartan showed improved posterior cerebral artery reactivity and restoration of functional hyperemia, this despite the fact that amyloid deposits in the brain did not decrease, and even showed a tendency to increase. Remarkably, losartan improved outcomes in cognitive tests in $\mathrm{AD}$ mice. At the cellular level, losartan decreased the oxidative state/stress and astrogliosis (Royea et al., 2017). These results are in agreement with those of another study in which losartan treatment improved cerebrovascular and cognitive function in older mice (12 months) (Ongali et al., 2014). These observations argue against a link between Ang II receptors and amyloid pathology-related cognitive dysfunction, but favor the idea that improving vascular function with the use of antihypertensive drugs could positively impact cognitive outcomes in $\mathrm{AD}$. In humans, telmisartan treatment was associated with increased resting $\mathrm{CBF}$ and improved cognitive function (Kume et al., 2012), supporting the use of antihypertensive treatments to improve vascular function and cerebral perfusion. In a randomized controlled trial, 6-month treatment with telmisartan, an $\mathrm{AT}_{1} \mathrm{R}$ blocker, in probable $\mathrm{AD}$ patients with essential hypertension decreased proinflammatory cytokines in the CSF and increased $\mathrm{A} \beta_{1-42}$, indicative of augmented clearance ( $\mathrm{Li}$ et al., 2012). An important point to consider, however, is 
that not all drugs that block Ang II receptors are helpful in restoring cognitive function (Trigiani et al., 2018) or are effective in long-established $\mathrm{AD}$ pathology, as seen in mice (Ongali et al., 2016).

The use of antihypertensive drugs has also been proposed as a strategy for ameliorating amyloid pathology. A recent study in which regulation of the RAS was enhanced through ACE2 in the Tg2676 mice model of AD showed that spatial memory was improved in association with a reduction in soluble and insoluble $\mathrm{A} \beta$ in the hippocampus (Evans et al., 2020). Here, however, vascular function was not evaluated. Ang-II-infused hypertensive mice exhibit increased production of amyloid precursor protein (APP) binding proteins (Csiszar et al., 2013). Yet, no changes in the production of APPprocessing enzymes that participate in the amyloidogenic process were found.

Further studies are needed to determine the effects of antihypertensive drugs and their mechanisms of action concerning the vascular component of $\mathrm{AD}$. These drugs might be useful in the prevention of $\mathrm{AD}$ and dementia by preserving vascular function. However, their potential to mitigate the contribution of amyloid pathology cannot be ruled out. In this latter context, it could be that the driver of amyloid pathology in hypertensive models and patients relates to the deleterious effects of hypoxia/ischemia on vascular function, as these conditions activate the processing of APP (Shiota et al., 2013).

Whether independent or as a result of hypertension, evidence also supports a link between arterial stiffness and AD pathology and related dementias. Notably, arterial stiffness is a contributing factor to pulsatile hemodynamics, cerebral hypoperfusion, and microvascular damage. In older adults, arterial stiffness is positively correlated with an increased incidence of cerebral small vessel disease (Hughes et al., 2015; Chirinos et al., 2019). RiveraRivera et al. (2020) showed that cerebrovascular stiffness was increased in middle-aged AD patients. In this work, the authors employed high temporal resolution 4D flow magnetic resonance imaging (MRI) to assess transcranial PWV in 160 participants classified according to cognitive function. They found that transcranial PWV was significantly increased in subjects with myocardial infarct or AD.

Notably, maladapted cerebral hemodynamics could lead to alterations in the structural and functional connectivity of the brain, as exemplified by white matter lesions/hyperintensities, a symptom of small vessel disease and parenchymal artery dysfunction (Bagi et al., 2018). At rest, the brain exhibits slow blood flow fluctuations that are interpreted as providing effective connectivity between regions comprising what is known as the default mode network (Raichle, 2015). Reduced functional connectivity between the hippocampus and other brain regions is found in AD patients (Allen et al., 2007), and has been shown to correlate with behavioral changes (Multani et al., 2019).

As is the case in hypertension and aging, diminished cerebral perfusion, perhaps initiated by morphological alterations of the microvasculature, may play a role in the development of $\mathrm{AD}$ through increases in oxidative stress and compromised neurovascular interactions. Decreased oxygen delivery to brain regions, including the hippocampus, leads to neurodegeneration and cognitive decline (de la Torre, 2000; Mehla et al., 2018). Tong et al. (2012) showed therapeutic benefits from simvastatin treatment in a mouse model of AD. Simvastatin lowered $\mathrm{O}_{2}^{-}$ production and normalized antioxidant superoxide dismutase 2 levels. Importantly, simvastatin restored cerebrovascular function and NVC in both aged (12 months) and adult mice (6 months). Short- and long-term memory was restored in aged adults but not aged $\mathrm{AD}$ mice, even without effects on plaque or amyloid $\beta(\mathrm{A} \beta$ ) levels.

At the level of the NVU, A $\beta$ has been shown to cause pericyteinduced capillary constriction in both $\mathrm{AD}$ patients and an $\mathrm{AD}$ mouse model. The underlying mechanism was found to involve the generation of ROS (mainly via NOX4), resulting in the release of the potent vasoconstrictor agent, endothelin-1 (ET-1). ET-1, in turn, acted through $\mathrm{ET}_{A}$ receptors to evoke pericyte constriction. Notably, $\mathrm{A} \beta$-evoked constrictions were prevented by blocking NOX4 or $\mathrm{ET}_{A}$ (Nortley et al., 2019). A recent study showed that secretion of APOE4 by pericytes resulted in activation of cyclophilin A and stimulation of downstream protein matrix metalloproteinase-9. Increased inflammation in pericytes, and possibly endothelial cells, increased BBB leakiness in the hippocampus and parahippocampus brain areas associated with learning and memory.

$\mathrm{A} \beta$ peptide aggregation in the wall of cerebral microvessels (cerebral amyloid angiopathy) also impairs vascular function (Kimbrough et al., 2015) and is a risk factor for vascular cognitive impairment. Using a combination of ex vivo and in vivo imaging approaches in mice, Kimbrough et al. (2015) found that astrocyte endfeet were separated from cerebral vessel segments that showed amyloid deposits and that astrocyte stimulation resulted in poor vascular responses. In contrast, astrocyte-induced vascular responses were intact in vessel segments that lacked amyloid deposits (Kimbrough et al., 2015). Collectively, these observations support a role for astrocytes in the regulation of $\mathrm{CBF}$ in $\mathrm{AD}$.

The importance of vascular homeostasis in $\mathrm{AD}$ and associated dementias has become an important shift in the quest to identify the factors contributing to cognitive decline (Csiszar et al., 2017). Collectively, the above findings call for controlled clinical trials and advanced animal models to help disentangle mechanisms targeted by antihypertensive and antioxidant treatments in the therapeutic benefits of these drugs in the setting of vascularrelated cognitive impairment and dementia.

\section{CONCLUSION}

This review highlights key crosstalk dynamics at the NVU, which maintain homeostasis in the brain (Figure 1). We discussed key molecular regulators of parenchymal arteriole vascular tone and the pathological changes these arterioles undergo in disease conditions, primarily hypertension. In addition, we describe how other components of the NVU (e.g., glial cells) may contribute to disease progression (Figure 1). Clearly, more work is needed to understand the cellular mechanisms underlying loss of function at the NVU and how vascular alterations (i.e., vascular stiffness, remodeling, and 
astrocyte-vascular uncoupling) impact homeostatic as well as energy-dependent processes in the brain. While vascular dysfunction is strongly linked to cognitive decline, many factors such as the cellular targets involved in disease-specific insults (i.e., $\mathrm{CBF}$, intravascular pressure, ischemia, inflammation) as well as the consequences these have on cerebral perfusion and neuronal functional remain ill define. Thus, future studies addressing the cellular and molecular players in the loss of physiological crosstalk at the NVU are needed to shed light on early processes, with therapeutic potential, to prevent what in later life manifests as vascular cognitive impairment and dementia.

\section{REFERENCES}

Albalawi, F., Lu, W., Beckel, J. M., Lim, J. C., McCaughey, S. A., and Mitchell, C. H. (2017). The P2X7 receptor primes IL-1beta and the NLRP3 inflammasome in astrocytes exposed to mechanical strain. Front. Cell. Neurosci. 11:227. doi: $10.3389 /$ fncel.2017.00227

Allen, G., Barnard, H., McColl, R., Hester, A. L., Fields, J. A., Weiner, M. F., et al. (2007). Reduced hippocampal functional connectivity in Alzheimer disease. Arch. Neurol. 64, 1482-1487. doi: 10.1001/archneur.64.10.1482

Alosco, M. L., Gunstad, J., Xu, X., Clark, U. S., Labbe, D. R., Riskin-Jones, H. H., et al. (2014). The impact of hypertension on cerebral perfusion and cortical thickness in older adults. J. Am. Soc. Hypertens. 8, 561-570. doi: 10.1016/j.jash. 2014.04.002

Angelova, P. R., and Abramov, A. Y. (2016). Functional role of mitochondrial reactive oxygen species in physiology. Free Radic. Biol. Med. 100, 81-85. doi: 10.1016/j.freeradbiomed.2016.06.005

Araque, A., Carmignoto, G., Haydon, P. G., Oliet, S. H., Robitaille, R., and Volterra, A. (2014). Gliotransmitters travel in time and space. Neuron 81, 728-739. doi: 10.1016/j.neuron.2014.02.007

Attwell, D., Buchan, A. M., Charpak, S., Lauritzen, M., Macvicar, B. A., and Newman, E. A. (2010). Glial and neuronal control of brain blood flow. Nature 468, 232-243. doi: 10.1038/nature09613

Avolio, A., Kim, M. O., Adji, A., Gangoda, S., Avadhanam, B., Tan, I., et al. (2018). Cerebral haemodynamics: effects of systemic arterial pulsatile function and hypertension. Curr. Hypertens. Rep. 20:20.

Badhwar, A., Lerch, J. P., Hamel, E., and Sled, J. G. (2013). Impaired structural correlates of memory in Alzheimer's disease mice. Neuroimage Clin. 3, 290-300. doi: 10.1016/j.nicl.2013.08.017

Bagher, P., and Segal, S. S. (2011). Regulation of blood flow in the microcirculation: role of conducted vasodilation. Acta Physiol (Oxf) 202, 271-284. doi: 10.1111/ j.1748-1716.2010.02244.x

Bagi, Z., Brandner, D. D., Le, P., McNeal, D. W., Gong, X., Dou, H., et al. (2018). Vasodilator dysfunction and oligodendrocyte dysmaturation in aging white matter. Ann. Neurol. 83, 142-152. doi: 10.1002/ana.25129

Baik, S. H., Kang, S., Lee, W., Choi, H., Chung, S., Kim, J. I., et al. (2019). A breakdown in metabolic reprogramming causes microglia dysfunction in Alzheimer's disease. Cell Metab. 30:e496.

Barthold, D., Joyce, G., Wharton, W., Kehoe, P., and Zissimopoulos, J. (2018). The association of multiple anti-hypertensive medication classes with Alzheimer's disease incidence across sex, race, and ethnicity. PLoS One 13:e0206705. doi: 10.1371/journal.pone.0206705

Baumbach, G. L., and Ghoneim, S. (1993). Vascular remodeling in hypertension. Scanning Microsc. 7, 137-142.

Bayliss, W. M. (1902). On the local reactions of the arterial wall to changes of internal pressure. J. Physiol. 28, 220-231. doi: 10.1113/jphysiol.1902.sp000911

Bazargani, N., and Attwell, D. (2016). Astrocyte calcium signaling: the third wave. Nat. Neurosci. 19, 182-189. doi: 10.1038/nn. 4201

Beckel, J. M., Argall, A. J., Lim, J. C., Xia, J., Lu, W., Coffey, E. E., et al. (2014). Mechanosensitive release of adenosine 5'-triphosphate through pannexin channels and mechanosensitive upregulation of pannexin channels in optic nerve head astrocytes: a mechanism for purinergic involvement in chronic strain. Glia 62, 1486-1501. doi: 10.1002/glia.22695

\section{AUTHOR CONTRIBUTIONS}

All authors listed have made a substantial, direct and intellectual contribution to the work, and approved it for publication.

\section{FUNDING}

This work was supported by funding from the National Institute of Neurological Disorders and Stroke (NINDS) (1R01NS08252101) of the NIH to JF.

Benetos, A., Petrovic, M., and Strandberg, T. (2019). Hypertension management in older and frail older patients. Circ. Res. 124, 1045-1060. doi: 10.1161/circresaha. 118.313236

Berthiaume, A. A., Grant, R. I., McDowell, K. P., Underly, R. G., Hartmann, D. A., Levy, M., et al. (2018a). Dynamic remodeling of pericytes in vivo maintains capillary coverage in the adult mouse brain. Cell Rep. 22, 8-16. doi: 10.1016/ j.celrep.2017.12.016

Berthiaume, A. A., Hartmann, D. A., Majesky, M. W., Bhat, N. R., and Shih, A. Y. (2018b). Pericyte structural remodeling in cerebrovascular health and homeostasis. Front. Aging Neurosci. 10:210. doi: 10.3389/fnagi.2018.00210

Bilbo, S., and Stevens, B. (2017). Microglia: the Brain's first responders. Cerebrum 2017:cer-14-17.

Bindocci, E., Savtchouk, I., Liaudet, N., Becker, D., Carriero, G., and Volterra, A. (2017). Three-dimensional Ca2+ imaging advances understanding of astrocyte biology. Science 356:eaai8185. doi: 10.1126/science.aai8185

Bonder, D. E., and McCarthy, K. D. (2014). Astrocytic Gq-GPCR-Linked IP3Rdependent $\mathrm{Ca} 2+$ signaling does not mediate neurovascular coupling in mouse visual cortex in vivo. J. Neurosci. 34, 13139-13150. doi: 10.1523/jneurosci.259114.2014

Bosch, A. J., Harazny, J. M., Kistner, I., Friedrich, S., Wojtkiewicz, J., and Schmieder, R. E. (2017). Retinal capillary rarefaction in patients with untreated mildmoderate hypertension. BMC Cardiovasc. Disord. 17:300. doi: 10.1186/s12872017-0732-x

Brayden, J. E., Li, Y., and Tavares, M. J. (2013). Purinergic receptors regulate myogenic tone in cerebral parenchymal arterioles. J. Cereb. Blood Flow Metab. 33, 293-299. doi: 10.1038/jcbfm.2012.169

Cai, C., Fordsmann, J. C., Jensen, S. H., Gesslein, B., Lonstrup, M., Hald, B. O., et al. (2018). Stimulation-induced increases in cerebral blood flow and local capillary vasoconstriction depend on conducted vascular responses. Proc. Natl. Acad. Sci. U.S.A. 115, E5796-E5804.

Calcinaghi, N., Wyss, M. T., Jolivet, R., Singh, A., Keller, A. L., Winnik, S., et al. (2013). Multimodal imaging in rats reveals impaired neurovascular coupling in sustained hypertension. Stroke 44, 1957-1964. doi: 10.1161/strokeaha.111. 000185

Cao, R., Higashikubo, B. T., Cardin, J., Knoblich, U., Ramos, R., Nelson, M. T., et al. (2009). Pinacidil induces vascular dilation and hyperemia in vivo and does not impact biophysical properties of neurons and astrocytes in vitro. Cleve. Clin. J. Med. 76(Suppl. 2), S80-S85.

Capone, C., Faraco, G., Park, L., Cao, X., Davisson, R. L., and Iadecola, C. (2011). The cerebrovascular dysfunction induced by slow pressor doses of angiotensin II precedes the development of hypertension. Am. J. Physiol. Heart Circ. Physiol. 300, H397-H407.

Capone, C., Faraco, G., Peterson, J. R., Coleman, C., Anrather, J., Milner, T. A., et al. (2012). Central cardiovascular circuits contribute to the neurovascular dysfunction in angiotensin II hypertension. J. Neurosci. 32, 4878-4886. doi: 10.1523/jneurosci.6262-11.2012

Chan, S. L., Nelson, M. T., and Cipolla, M. J. (2019). Transient receptor potential vanilloid-4 channels are involved in diminished myogenic tone in brain parenchymal arterioles in response to chronic hypoperfusion in mice. Acta Physiol. 225:e13181. doi: 10.1111/apha.13181

Chen, B. R., Bouchard, M. B., McCaslin, A. F., Burgess, S. A., and Hillman, E. M. (2011). High-speed vascular dynamics of the hemodynamic response. Neuroimage 54, 1021-1030. doi: 10.1016/j.neuroimage.2010.09.036 
Chen, B. R., Kozberg, M. G., Bouchard, M. B., Shaik, M. A., and Hillman, E. M. (2014). A critical role for the vascular endothelium in functional neurovascular coupling in the brain. J. Am. Heart Assoc. 3:e000787.

Chiesa, S. T., Masi, S., Shipley, M. J., Ellins, E. A., Fraser, A. G., Hughes, A. D., et al. (2019). Carotid artery wave intensity in mid- to late-life predicts cognitive decline: the Whitehall II study. Eur. Heart J. 40, 2300-2309. doi: 10.1093/ eurheartj/ehz189

Chirinos, J. A., Segers, P., Hughes, T., and Townsend, R. (2019). Large-artery stiffness in health and disease: JACC state-of-the-art review. J. Am. Coll. Cardiol. 74, 1237-1263. doi: 10.1016/j.jacc.2019.07.012

Choi, H. J., Sun, D., and Jakobs, T. C. (2015). Astrocytes in the optic nerve head express putative mechanosensitive channels. Mol. Vis. 21, 749-766.

Cipolla, M. J. (2009). The Cerebral Circulation. San Rafael, CA: Morgan \& Claypool Life.

Cipolla, M. J., Sweet, J., Chan, S. L., Tavares, M. J., Gokina, N., and Brayden, J. E. (2014). Increased pressure-induced tone in rat parenchymal arterioles vs. middle cerebral arteries: role of ion channels and calcium sensitivity. J. Appl. Physiol. 117, 53-59. doi: 10.1152/japplphysiol.00253.2014

Clarke, L. E., Liddelow, S. A., Chakraborty, C., Munch, A. E., Heiman, M., and Barres, B. A. (2018). Normal aging induces A1-like astrocyte reactivity. Proc. Natl. Acad. Sci. U.S.A. 115, E1896-E1905.

Climie, R. E., Gallo, A., Picone, D. S., Di Lascio, N., van Sloten, T. T., Guala, A., et al. (2019). Measuring the interaction between the macro- and micro-vasculature. Front. Cardiovasc. Med. 6:169. doi: 10.3389/fcvm.2019.00169

Cornell-Bell, A. H., Finkbeiner, S. M., Cooper, M. S., and Smith, S. J. (1990). Glutamate induces calcium waves in cultured astrocytes: long-range glial signaling. Science 247, 470-473. doi: 10.1126/science.1967852

Csiszar, A., Tarantini, S., Fulop, G. A., Kiss, T., Valcarcel-Ares, M. N., Galvan, V., et al. (2017). Hypertension impairs neurovascular coupling and promotes microvascular injury: role in exacerbation of Alzheimer's disease. Geroscience 39, 359-372. doi: 10.1007/s11357-017-9991-9

Csiszar, A., Tucsek, Z., Toth, P., Sosnowska, D., Gautam, T., Koller, A., et al. (2013). Synergistic effects of hypertension and aging on cognitive function and hippocampal expression of genes involved in beta-amyloid generation and Alzheimer's disease. Am. J. Physiol. Heart Circ. Physiol. 305, H1120-H1130.

de Jong, D. L. K., Tarumi, T., Liu, J., Zhang, R., and Claassen, J. (2017). Lack of linear correlation between dynamic and steady-state cerebral autoregulation. J. Physiol. 595, 5623-5636. doi: 10.1113/jp274304

de la Torre, J. C. (2000). Critically attained threshold of cerebral hypoperfusion: the CATCH hypothesis of Alzheimer's pathogenesis. Neurobiol. Aging 21, 331-342. doi: 10.1016/s0197-4580(00)00111-1

De Miguel, C., Rudemiller, N. P., Abais, J. M., and Mattson, D. L. (2015). Inflammation and hypertension: new understandings and potential therapeutic targets. Curr. Hypertens. Rep. 17:507.

De Silva, T. M., and Faraci, F. M. (2020). Contributions of aging to cerebral small vessel disease. Annu. Rev. Physiol. 82, 275-295.

Delekate, A., Fuchtemeier, M., Schumacher, T., Ulbrich, C., Foddis, M., and Petzold, G. C. (2014). Metabotropic P2Y1 receptor signalling mediates astrocytic hyperactivity in vivo in an Alzheimer's disease mouse model. Nat. Commun. 5:5422.

Devor, A., Sakadzic, S., Saisan, P. A., Yaseen, M. A., Roussakis, E., Srinivasan, V. J., et al. (2011). "Overshoot" of $\mathrm{O}(2)$ is required to maintain baseline tissue oxygenation at locations distal to blood vessels. J. Neurosci. 31, 13676-13681. doi: 10.1523/jneurosci.1968-11.2011

Diaz, J. R., Kim, K. J., Brands, M. W., and Filosa, J. A. (2019). Augmented astrocyte microdomain $\mathrm{Ca}(2+)$ dynamics and parenchymal arteriole tone in angiotensin II-infused hypertensive mice. Glia 67, 551-565. doi: 10.1002/glia.23564

Diaz-Otero, J. M., Fisher, C., Downs, K., Moss, M. E., Jaffe, I. Z., Jackson, W. F., et al. (2017). Endothelial mineralocorticoid receptor mediates parenchymal arteriole and posterior cerebral artery remodeling during angiotensin II-Induced hypertension. Hypertension 70, 1113-1121. doi: 10.1161/hypertensionaha.117. 09598

Diaz-Otero, J. M., Garver, H., Fink, G. D., Jackson, W. F., and Dorrance, A. M. (2016). Aging is associated with changes to the biomechanical properties of the posterior cerebral artery and parenchymal arterioles. Am. J. Physiol. Heart Circ. Physiol. 310, H365-H375.

Diaz-Otero, J. M., Yen, T. C., Ahmad, A., Laimon-Thomson, E., Abolibdeh, B., Kelly, K., et al. (2019). Transient receptor potential vanilloid 4 channels are important regulators of parenchymal arteriole dilation and cognitive function. Microcirculation 26:e12535.

Diaz-Otero, J. M., Yen, T. C., Fisher, C., Bota, D., Jackson, W. F., and Dorrance, A. M. (2018). Mineralocorticoid receptor antagonism improves parenchymal arteriole dilation via a TRPV4-dependent mechanism and prevents cognitive dysfunction in hypertension. Am. J. Physiol. Heart Circ. Physiol. 315, H1304H1315.

Dickinson, C. J., and Thomason, A. D. (1959). Vertebral and internal carotid arteries in relation to hypertension and cerebrovascular disease. Lancet 2, 46-48. doi: 10.1016/s0140-6736(59)90494-5

Ding, J., Davis-Plourde, K. L., Sedaghat, S., Tully, P. J., Wang, W., Phillips, C., et al. (2020). Antihypertensive medications and risk for incident dementia and Alzheimer's disease: a meta-analysis of individual participant data from prospective cohort studies. Lancet Neurol. 19, 61-70. doi: 10.1016/s14744422(19)30393-x

Ding, S., Wang, T., Cui, W., and Haydon, P. G. (2009). Photothrombosis ischemia stimulates a sustained astrocytic Ca2+ signaling in vivo. Glia 57, 767-776. doi: 10.1002/glia.20804

Dunn, K. M., Hill-Eubanks, D. C., Liedtke, W. B., and Nelson, M. T. (2013). TRPV4 channels stimulate $\mathrm{Ca} 2+$-induced $\mathrm{Ca} 2+$ release in astrocytic endfeet and amplify neurovascular coupling responses. Proc. Natl. Acad. Sci. U.S.A. 110, 6157-6162. doi: 10.1073/pnas.1216514110

Edwards Iii, G. A., Gamez, N., Escobedo, G. Jr., Calderon, O., and MorenoGonzalez, I. (2019). Modifiable risk factors for Alzheimer's disease. Front. Aging Neurosci. 11:146. doi: 10.3389/fnagi.2019.00146

Elting, J. W., Sanders, M. L., Panerai, R. B., Aries, M., Bor-Seng-Shu, E., Caicedo, A., et al. (2020). Assessment of dynamic cerebral autoregulation in humans: Is reproducibility dependent on blood pressure variability? PLoS One 15:e0227651. doi: 10.1371/journal.pone.0227651

Evans, C. E., Miners, J. S., Piva, G., Willis, C. L., Heard, D. M., Kidd, E. J., et al. (2020). ACE2 activation protects against cognitive decline and reduces amyloid pathology in the Tg2576 mouse model of Alzheimer's disease. Acta Neuropathol. 139, 485-502. doi: 10.1007/s00401-019-02098-6

Faraci, F. M. (2018). Watching small vessel disease grow. Circ. Res. 122, 810-812. doi: $10.1161 /$ circresaha.118.312762

Faraco, G., and Iadecola, C. (2013). Hypertension: a harbinger of stroke and dementia. Hypertension 62, 810-817. doi: 10.1161/hypertensionaha.113.01063

Faraco, G., Sugiyama, Y., Lane, D., Garcia-Bonilla, L., Chang, H., Santisteban, M. M., et al. (2016). Perivascular macrophages mediate the neurovascular and cognitive dysfunction associated with hypertension. J. Clin. Invest. 126, 4674-4689. doi: 10.1172/jci86950

Figueroa, X. F., and Duling, B. R. (2009). Gap junctions in the control of vascular function. Antioxid. Redox Signal. 11, 251-266. doi: 10.1089/ars.2008.2117

Fok, H., Guilcher, A., Brett, S., Jiang, B., Li, Y., Epstein, S., et al. (2014). Dominance of the forward compression wave in determining pulsatile components of blood pressure: similarities between inotropic stimulation and essential hypertension. Hypertension 64, 1116-1123. doi: 10.1161/hypertensionaha.114. 04050

Forrester, S. J., Booz, G. W., Sigmund, C. D., Coffman, T. M., Kawai, T., Rizzo, V., et al. (2018). Angiotensin II signal transduction: an update on mechanisms of physiology and pathophysiology. Physiol. Rev. 98, 1627-1738. doi: 10.1152/ physrev.00038.2017

Girouard, H., and Iadecola, C. (2006). Neurovascular coupling in the normal brain and in hypertension, stroke, and Alzheimer disease. J. Appl. Physiol. 100, 328-335. doi: 10.1152/japplphysiol.00966.2005

Grosche, J., Matyash, V., Moller, T., Verkhratsky, A., Reichenbach, A., and Kettenmann, H. (1999). Microdomains for neuron-glia interaction: parallel fiber signaling to Bergmann glial cells. Nat. Neurosci. 2, 139-143. doi: 10.1038/ 5692

Grutzendler, J., and Nedergaard, M. (2019). Cellular control of brain capillary blood flow: in vivo imaging veritas. Trends Neurosci. 42, 528-536. doi: 10.1016/ j.tins.2019.05.009

Guo, Y., Li, X., Zhang, M., Chen, N., Wu, S., Lei, J., et al. (2019). Age and brain regionassociated alterations of cerebral blood flow in early Alzheimer's disease assessed in AbetaPPSWE/PS1DeltaE9 transgenic mice using arterial spin labeling. Mol. Med. Rep. 19, 3045-3052.

Hakim, A. M. (2019). Small vessel disease. Front. Neurol. 10:1020. doi: 10.3389/ fneur.2019.01020 
Halder, S. K., and Milner, R. (2019). A critical role for microglia in maintaining vascular integrity in the hypoxic spinal cord. Proc. Natl. Acad. Sci. U.S.A. 116, 26029-26037. doi: 10.1073/pnas.1912178116

Hall, C. N., Reynell, C., Gesslein, B., Hamilton, N. B., Mishra, A., Sutherland, B. A., et al. (2014). Capillary pericytes regulate cerebral blood flow in health and disease. Nature 508, 55-60. doi: 10.1038/nature13165

Hanisch, U. K., and Kettenmann, H. (2007). Microglia: active sensor and versatile effector cells in the normal and pathologic brain. Nat. Neurosci. 10, 1387-1394. doi: $10.1038 / \mathrm{nn} 1997$

Harraz, O. F., Hill-Eubanks, D., and Nelson, M. T. (2020). PIP2: a critical regulator of vascular ion channels hiding in plain sight. Proc. Natl. Acad. Sci. U.S.A. 117, 20378-20389. doi: 10.1073/pnas.2006737117

Harraz, O. F., Longden, T. A., Dabertrand, F., Hill-Eubanks, D., and Nelson, M. T. (2018a). Endothelial GqPCR activity controls capillary electrical signaling and brain blood flow through PIP2 depletion. Proc. Natl. Acad. Sci. U.S.A. 115, E3569-E3577.

Harraz, O. F., Longden, T. A., Hill-Eubanks, D., and Nelson, M. T. (2018b). PIP2 depletion promotes TRPV4 channel activity in mouse brain capillary endothelial cells. eLife 7:e38689.

Hebert, F., Grand'maison, M., Ho, M. K., Lerch, J. P., Hamel, E., and Bedell, B. J. (2013). Cortical atrophy and hypoperfusion in a transgenic mouse model of Alzheimer's disease. Neurobiol. Aging 34, 1644-1652. doi: 10.1016/ j.neurobiolaging.2012.11.022

Henskens, L. H., Kroon, A. A., van Oostenbrugge, R. J., Gronenschild, E. H., Fuss-Lejeune, M. M., Hofman, P. A., et al. (2008). Increased aortic pulse wave velocity is associated with silent cerebral small-vessel disease in hypertensive patients. Hypertension 52, 1120-1126. doi: 10.1161/hypertensionaha.108. 119024

Hill, M. A., Davis, M. J., Meininger, G. A., Potocnik, S. J., and Murphy, T. V. (2006). Arteriolar myogenic signalling mechanisms: implications for local vascular function. Clin. Hemorheol. Microcirc. 34, 67-79.

Hill-Eubanks, D. C., Gonzales, A. L., Sonkusare, S. K., and Nelson, M. T. (2014). Vascular TRP channels: performing under pressure and going with the flow. Physiology 29, 343-360. doi: 10.1152/physiol.00009.2014

Hosford, P. S., and Gourine, A. V. (2019). What is the key mediator of the neurovascular coupling response? Neurosci. Biobehav. Rev. 96, 174-181. doi: 10.1016/j.neubiorev.2018.11.011

Hu, X., De Silva, T. M., Chen, J., and Faraci, F. M. (2017). Cerebral vascular disease and neurovascular injury in ischemic stroke. Circ. Res. 120, 449-471. doi: 10.1161/circresaha.116.308427

Hughes, T. M., Craft, S., and Lopez, O. L. (2015). Review of 'the potential role of arterial stiffness in the pathogenesis of Alzheimer's disease'. Neurodegener. Dis. Manage. 5, 121-135. doi: 10.2217/nmt.14.53

Iadecola, C. (2013). The pathobiology of vascular dementia. Neuron 80, 844-866. doi: $10.1016 /$ j.neuron.2013.10.008

Iadecola, C. (2017). The neurovascular unit coming of age: a journey through neurovascular coupling in health and disease. Neuron 96, 17-42. doi: 10.1016/ j.neuron.2017.07.030

Iadecola, C., Yang, G., Ebner, T. J., and Chen, G. (1997). Local and propagated vascular responses evoked by focal synaptic activity in cerebellar cortex. J. Neurophysiol. 78, 651-659. doi: 10.1152/jn.1997.78. 2.651

Iddings, J. A., Kim, K. J., Zhou, Y., Higashimori, H., and Filosa, J. A. (2015). Enhanced parenchymal arteriole tone and astrocyte signaling protect neurovascular coupling mediated parenchymal arteriole vasodilation in the spontaneously hypertensive rat. J. Cereb. Blood Flow Metab. 35, 1127-1136. doi: $10.1038 /$ jcbfm.2015.31

Iliff, J. J., Wang, M., Liao, Y., Plogg, B. A., Peng, W., Gundersen, G. A., et al. (2012). A paravascular pathway facilitates CSF flow through the brain parenchyma and the clearance of interstitial solutes, including amyloid beta. Sci. Transl. Med. 4:147ra111. doi: 10.1126/scitranslmed.3003748

Iliff, J. J., Wang, M., Zeppenfeld, D. M., Venkataraman, A., Plog, B. A., Liao, Y., et al. (2013). Cerebral arterial pulsation drives paravascular CSF-interstitial fluid exchange in the murine brain. J. Neurosci. 33, 18190-18199. doi: 10.1523/ jneurosci.1592-13.2013

Intengan, H. D., and Schiffrin, E. L. (2001). Vascular remodeling in hypertension. Hypertension 38, 581-587. doi: 10.1161/hy09t1.096249
Iturria-Medina, Y., Sotero, R. C., Toussaint, P. J., Mateos-Perez, J. M., Evans, A. C., Alzheimer's Disease, et al. (2016). Early role of vascular dysregulation on lateonset Alzheimer's disease based on multifactorial data-driven analysis. Nat. Commun. 7:11934.

Iulita, M. F., Duchemin, S., Vallerand, D., Barhoumi, T., Alvarez, F., Istomine, R., et al. (2019). CD4(+) regulatory T lymphocytes prevent impaired cerebral blood flow in angiotensin II-induced hypertension. J. Am. Heart Assoc. 8, e009372.

Johnson, A. W., Kinzenbaw, D. A., Modrick, M. L., and Faraci, F. M. (2013). Small-molecule inhibitors of signal transducer and activator of transcription 3 protect against angiotensin II-induced vascular dysfunction and hypertension. Hypertension 61, 437-442. doi: 10.1161/hypertensionaha.111.00299

Jolivel, V., Bicker, F., Biname, F., Ploen, R., Keller, S., Gollan, R., et al. (2015). Perivascular microglia promote blood vessel disintegration in the ischemic penumbra. Acta Neuropathol. 129, 279-295. doi: 10.1007/s00401-014-1372-1

Joutel, A., and Chabriat, H. (2017). Pathogenesis of white matter changes in cerebral small vessel diseases: beyond vessel-intrinsic mechanisms. Clin. Sci. 131, 635-651. doi: 10.1042/cs20160380

Joutel, A., and Faraci, F. M. (2014). Cerebral small vessel disease: insights and opportunities from mouse models of collagen IV-related small vessel disease and cerebral autosomal dominant arteriopathy with subcortical infarcts and leukoencephalopathy. Stroke 45, 1215-1221. doi: 10.1161/strokeaha.113. 002878

Jukovskaya, N., Tiret, P., Lecoq, J., and Charpak, S. (2011). What does local functional hyperemia tell about local neuronal activation? J. Neurosci. 31, 1579-1582. doi: 10.1523/jneurosci.3146-10.2011

Kanemaru, K., Sekiya, H., Xu, M., Satoh, K., Kitajima, N., Yoshida, K., et al. (2014). In vivo visualization of subtle, transient, and local activity of astrocytes using an ultrasensitive $\mathrm{Ca}(2+)$ indicator. Cell Rep. 8, 311-318. doi: 10.1016/j.celrep. 2014.05.056

Katsi, V., Marketou, M., Maragkoudakis, S., Didagelos, M., Charalambous, G., Parthenakis, F., et al. (2020). Blood-brain barrier dysfunction: the undervalued frontier of hypertension. J. Hum. Hypertens. doi: 10.1038/s41371-020-0352-2 [Epub ahead of print].

Kazama, K., Anrather, J., Zhou, P., Girouard, H., Frys, K., Milner, T. A., et al. (2004). Angiotensin II impairs neurovascular coupling in neocortex through NADPH oxidase-derived radicals. Circ. Res. 95, 1019-1026. doi: 10.1161/01. res.0000148637.85595.c5

Kim, K. J., Iddings, J. A., Stern, J. E., Blanco, V. M., Croom, D., Kirov, S. A., et al. (2015). Astrocyte contributions to flow/pressure-evoked parenchymal arteriole vasoconstriction. J. Neurosci. 35, 8245-8257. doi: 10.1523/jneurosci.4486-14. 2015

Kim, K. J., Ramiro Diaz, J., Iddings, J. A., and Filosa, J. A. (2016). Vasculo-neuronal coupling: retrograde vascular communication to brain neurons. J. Neurosci. 36, 12624-12639. doi: 10.1523/jneurosci.1300-16.2016

Kimbrough, I. F., Robel, S., Roberson, E. D., and Sontheimer, H. (2015). Vascular amyloidosis impairs the gliovascular unit in a mouse model of Alzheimer's disease. Brain 138, 3716-3733. doi: 10.1093/brain/awv327

Koller, A., and Toth, P. (2012). Contribution of flow-dependent vasomotor mechanisms to the autoregulation of cerebral blood flow. J. Vasc. Res. 49, 375-389. doi: 10.1159/000338747

Kozlov, A. S., Angulo, M. C., Audinat, E., and Charpak, S. (2006). Target cellspecific modulation of neuronal activity by astrocytes. Proc. Natl. Acad. Sci. U.S.A. 103, 10058-10063. doi: 10.1073/pnas.0603741103

Kress, B. T., Iliff, J. J., Xia, M., Wang, M., Wei, H. S., Zeppenfeld, D., et al. (2014). Impairment of paravascular clearance pathways in the aging brain. Ann. Neurol. 76, 845-861. doi: 10.1002/ana.24271

Krizaj, D., Ryskamp, D. A., Tian, N., Tezel, G., Mitchell, C. H., Slepak, V. Z., et al. (2014). From mechanosensitivity to inflammatory responses: new players in the pathology of glaucoma. Curr. Eye Res. 39, 105-119. doi: 10.3109/02713683. 2013.836541

Kume, K., Hanyu, H., Sakurai, H., Takada, Y., Onuma, T., and Iwamoto, T. (2012). Effects of telmisartan on cognition and regional cerebral blood flow in hypertensive patients with Alzheimer's disease. Geriatr. Gerontol. Int. 12, 207-214. doi: 10.1111/j.1447-0594.2011.00746.x

Lacolley, P., Regnault, V., and Avolio, A. P. (2018). Smooth muscle cell and arterial aging: basic and clinical aspects. Cardiovasc. Res. 114, 513-528. doi: 10.1093/ cvr/cvy009 
Lapato, A. S., and Tiwari-Woodruff, S. K. (2018). Connexins and pannexins: at the junction of neuro-glial homeostasis \& disease. J. Neurosci. Res. 96, 31-44. doi: $10.1002 /$ jnr. 24088

Lavi, S., Gaitini, D., Milloul, V., and Jacob, G. (2006). Impaired cerebral CO2 vasoreactivity: association with endothelial dysfunction. Am. J. Physiol. Heart Circ. Physiol. 291, H1856-H1861.

Li, W., Zhang, J. W., Lu, F., Ma, M. M., Wang, J. Q., Suo, A. Q., et al. (2012). [Effects of telmisartan on the level of Abeta1-42, interleukin-1beta, tumor necrosis factor alpha and cognition in hypertensive patients with Alzheimer's disease]. Zhonghua Yi Xue Za Zhi 92, 2743-2746.

Li, Y., Baylie, R. L., Tavares, M. J., and Brayden, J. E. (2014). TRPM4 channels couple purinergic receptor mechanoactivation and myogenic tone development in cerebral parenchymal arterioles. J. Cereb. Blood Flow Metab. 34, 1706-1714. doi: $10.1038 /$ jcbfm.2014.139

Liddelow, S. A., Guttenplan, K. A., Clarke, L. E., Bennett, F. C., Bohlen, C. J., Schirmer, L., et al. (2017). Neurotoxic reactive astrocytes are induced by activated microglia. Nature 541, 481-487.

Liu, J., Tseng, B. Y., Khan, M. A., Tarumi, T., Hill, C., Mirshams, N., et al. (2016). Individual variability of cerebral autoregulation, posterior cerebral circulation and white matter hyperintensity. J. Physiol. 594, 3141-3155. doi: 10.1113/ jp271068

Livingston, G., Sommerlad, A., Orgeta, V., Costafreda, S. G., Huntley, J., Ames, D., et al. (2017). Dementia prevention, intervention, and care. Lancet 390, 2673-2734.

Longden, T. A., Dabertrand, F., Koide, M., Gonzales, A. L., Tykocki, N. R., Brayden, J. E., et al. (2017). Capillary K+-sensing initiates retrograde hyperpolarization to increase local cerebral blood flow. Nat. Neurosci. 20, 717-726. doi: 10.1038/nn. 4533

Lopes, R. A., Neves, K. B., Tostes, R. C., Montezano, A. C., and Touyz, R. M. (2015). Downregulation of nuclear factor erythroid 2-related factor and associated antioxidant genes contributes to redox-sensitive vascular dysfunction in hypertension. Hypertension 66, 1240-1250. doi: 10.1161/hypertensionaha.115. 06163

Lovatt, D., Sonnewald, U., Waagepetersen, H. S., Schousboe, A., He, W., Lin, J. H., et al. (2007). The transcriptome and metabolic gene signature of protoplasmic astrocytes in the adult murine cortex. J. Neurosci. 27, 12255-12266. doi: 10. 1523/jneurosci.3404-07.2007

Lu, X., Moeini, M., Li, B., Lu, Y., Damseh, R., Pouliot, P., et al. (2019). A pilot study investigating changes in capillary hemodynamics and its modulation by exercise in the APP-PS1 Alzheimer mouse model. Front. Neurosci. 13:1261. doi: 10.3389/fnins.2019.01261

Lundgaard, I., Osorio, M. J., Kress, B. T., Sanggaard, S., and Nedergaard, M. (2014). White matter astrocytes in health and disease. Neuroscience 276, 161-173. doi: 10.1016/j.neuroscience.2013.10.050

Marmarelis, V. Z., Shin, D. C., Oesterreich, M., and Mueller, M. (2020). Quantification of dynamic cerebral autoregulation and $\mathrm{CO} 2$ dynamic vasomotor reactivity impairment in essential hypertension. J. Appl. Physiol. 128, 397-409. doi: 10.1152/japplphysiol.00620.2019

Marvar, P. J., Hendy, E. B., Cruise, T. D., Walas, D., DeCicco, D., Vadigepalli, R., et al. (2016). Systemic leukotriene B4 receptor antagonism lowers arterial blood pressure and improves autonomic function in the spontaneously hypertensive rat. J. Physiol. 594, 5975-5989. doi: 10.1113/ jp272065

Matin, N., Pires, P. W., Garver, H., Jackson, W. F., and Dorrance, A. M. (2016). DOCA-salt hypertension impairs artery function in rat middle cerebral artery and parenchymal arterioles. Microcirculation 23, 571-579. doi: 10.1111/micc. 12308

McBryde, F. D., Malpas, S. C., and Paton, J. F. (2017). Intracranial mechanisms for preserving brain blood flow in health and disease. Acta Physiol. 219, 274-287. doi: 10.1111/apha.12706

Mehla, J., Lacoursiere, S., Stuart, E., McDonald, R. J., and Mohajerani, M. H. (2018). Gradual cerebral hypoperfusion impairs fear conditioning and object recognition learning and memory in mice: potential roles of neurodegeneration and cholinergic dysfunction. J. Alzheimers Dis. 61, 283-293. doi: 10.3233/jad170635

Merkler, A. E., and Iadecola, C. (2017). Rollercoaster blood pressure: An Alzheimer disease risk factor? Circulation 136, 526-528. doi: 10.1161/circulationaha.117. 029618
Miller, S. J. (2018). Astrocyte heterogeneity in the adult central nervous system. Front. Cell. Neurosci. 12:401.

Minelli, A., Castaldo, P., Gobbi, P., Salucci, S., Magi, S., and Amoroso, S. (2007). Cellular and subcellular localization of $\mathrm{Na}+\mathrm{Ca} 2+$ exchanger protein isoforms, NCX1, NCX2, and NCX3 in cerebral cortex and hippocampus of adult rat. Cell Calcium 41, 221-234. doi: 10.1016/j.ceca.2006.06.004

Mishra, A., Reynolds, J. P., Chen, Y., Gourine, A. V., Rusakov, D. A., and Attwell, D. (2016). Astrocytes mediate neurovascular signaling to capillary pericytes but not to arterioles. Nat. Neurosci. 19, 1619-1627. doi: 10.1038/nn.4428

Mitchell, G. F. (2018). Aortic stiffness, pressure and flow pulsatility, and target organ damage. J. Appl. Physiol. 125, 1871-1880. doi: 10.1152/japplphysiol. 00108.2018

Mitchell, G. F., van Buchem, M. A., Sigurdsson, S., Gotal, J. D., Jonsdottir, M. K., Kjartansson, O., et al. (2011). Arterial stiffness, pressure and flow pulsatility and brain structure and function: the Age, Gene/Environment SusceptibilityReykjavik study. Brain 134, 3398-3407. doi: 10.1093/brain/awr253

Mogi, M. (2019). Could management of blood pressure prevent dementia in the elderly? Clin. Hypertens. 25:27.

Montagne, A., Nation, D. A., Sagare, A. P., Barisano, G., Sweeney, M. D., Chakhoyan, A., et al. (2020). APOE4 leads to blood-brain barrier dysfunction predicting cognitive decline. Nature 581, 71-76.

Montezano, A. C., Dulak-Lis, M., Tsiropoulou, S., Harvey, A., Briones, A. M., and Touyz, R. M. (2015). Oxidative stress and human hypertension: vascular mechanisms, biomarkers, and novel therapies. Can. J. Cardiol. 31, 631-641. doi: 10.1016/j.cjca.2015.02.008

Moore, C. I., and Cao, R. (2008). The hemo-neural hypothesis: on the role of blood flow in information processing. J. Neurophysiol. 99, 2035-2047. doi: 10.1152/jn.01366.2006

Morrison, H. W., and Filosa, J. A. (2016). Sex differences in astrocyte and microglia responses immediately following middle cerebral artery occlusion in adult mice. Neuroscience 339, 85-99. doi: 10.1016/j.neuroscience.2016.09.047

Morrison, H. W., and Filosa, J. A. (2019). Stroke and the neurovascular unit: glial cells, sex differences, and hypertension. Am. J. Physiol. Cell Physiol. 316, C325-C339.

Mortensen, K. N., Sanggaard, S., Mestre, H., Lee, H., Kostrikov, S., Xavier, A. L. R., et al. (2019). Impaired glymphatic transport in spontaneously hypertensive rats. J. Neurosci. 39, 6365-6377. doi: 10.1523/jneurosci.1974-18.2019

Moshkforoush, A., Ashenagar, B., Harraz, O. F., Dabertrand, F., Longden, T. A., Nelson, M. T., et al. (2020). The capillary Kir channel as sensor and amplifier of neuronal signals: modeling insights on $\mathrm{K}(+)$-mediated neurovascular communication. Proc. Natl. Acad. Sci. U.S.A. 117, 16626-16637. doi: 10.1073/ pnas. 2000151117

Multani, N., Taghdiri, F., Anor, C. J., Varriano, B., Misquitta, K., Tang-Wai, D. F., et al. (2019). Association between social cognition changes and resting state functional connectivity in frontotemporal dementia, Alzheimer's Disease, Parkinson's disease, and healthy controls. Front. Neurosci. 13:1259. doi: 10. 3389/fnins.2019.01259

Munoz, M. F., Puebla, M., and Figueroa, X. F. (2015). Control of the neurovascular coupling by nitric oxide-dependent regulation of astrocytic $\mathrm{Ca}(2+)$ signaling. Front. Cell. Neurosci. 9:59. doi: 10.3389/fncel.2015.00059

Nakazato, R., Kawabe, K., Yamada, D., Ikeno, S., Mieda, M., Shimba, S., et al. (2017). Disruption of bmall impairs blood-brain barrier integrity via pericyte dysfunction. J. Neurosci. 37, 10052-10062. doi: 10.1523/jneurosci.3639-16.2017

Negoita, M., Hughes, A. D., Parker, K. H., and Khir, A. W. (2018). A method for determining local pulse wave velocity in human ascending aorta from sequential ultrasound measurements of diameter and velocity. Physiol. Meas. 39:114009. doi: 10.1088/1361-6579/aae8a0

Nguyen, M. D., and Venton, B. J. (2015). Fast-scan cyclic voltammetry for the characterization of rapid adenosine release. Comput. Struct. Biotechnol. J. 13, 47-54. doi: 10.1016/j.csbj.2014.12.006

Nizar, K., Uhlirova, H., Tian, P., Saisan, P. A., Cheng, Q., Reznichenko, L., et al. (2013). In vivo stimulus-induced vasodilation occurs without IP3 receptor activation and may precede astrocytic calcium increase. J. Neurosci. 33, 84118422. doi: 10.1523/jneurosci.3285-12.2013

Nortley, R., Korte, N., Izquierdo, P., Hirunpattarasilp, C., Mishra, A., Jaunmuktane, Z., et al. (2019). Amyloid beta oligomers constrict human capillaries in Alzheimer's disease via signaling to pericytes. Science 365:eaav9518. doi: 10. $1126 /$ science.aav9518 
Ohara, H., and Nabika, T. (2016). A nonsense mutation of Stiml identified in stroke-prone spontaneously hypertensive rats decreased the store-operated calcium entry in astrocytes. Biochem. Biophys. Res. Commun. 476, 406-411. doi: 10.1016/j.bbrc.2016.05.134

Oheim, M., Schmidt, E., and Hirrlinger, J. (2018). Local energy on demand: Are 'spontaneous' astrocytic $\mathrm{Ca}(2+)$-microdomains the regulatory unit for astrocyte-neuron metabolic cooperation? Brain Res. Bull. 136, 54-64. doi: 10.1016/j.brainresbull.2017.04.011

O’Herron, P., Chhatbar, P. Y., Levy, M., Shen, Z., Schramm, A. E., Lu, Z., et al. (2016). Neural correlates of single-vessel haemodynamic responses in vivo. Nature 534, 378-382. doi: 10.1038/nature17965

Oishi, E., Ohara, T., Sakata, S., Fukuhara, M., Hata, J., Yoshida, D., et al. (2017). Day-to-day blood pressure variability and risk of dementia in a general japanese elderly population: the hisayama study. Circulation 136, 516-525. doi: 10.1161/ circulationaha.116.025667

Ongali, B., Nicolakakis, N., Tong, X. K., Aboulkassim, T., Imboden, H., and Hamel, E. (2016). Enalapril alone or co-administered with losartan rescues cerebrovascular dysfunction, but not mnemonic deficits or amyloidosis in a mouse model of Alzheimer's disease. J. Alzheimers Dis. 51, 1183-1195. doi: 10.3233/jad- 150868

Ongali, B., Nicolakakis, N., Tong, X. K., Aboulkassim, T., Papadopoulos, P., RosaNeto, P., et al. (2014). Angiotensin II type 1 receptor blocker losartan prevents and rescues cerebrovascular, neuropathological and cognitive deficits in an Alzheimer's disease model. Neurobiol. Dis. 68, 126-136. doi: 10.1016/j.nbd. 2014.04.018

Padmanabhan, S., Caulfield, M., and Dominiczak, A. F. (2015). Genetic and molecular aspects of hypertension. Circ. Res. 116, 937-959. doi: 10.1161/ circresaha.116.303647

Parati, G., Ochoa, J. E., and Bilo, G. (2012). Blood pressure variability, cardiovascular risk, and risk for renal disease progression. Curr. Hypertens. Rep. 14, 421-431. doi: 10.1007/s11906-012-0290-7

Pires, P. W., Dams Ramos, C. M., Matin, N., and Dorrance, A. M. (2013). The effects of hypertension on the cerebral circulation. Am. J. Physiol. Heart Circ. Physiol. 304, H1598-H1614. doi: 10.1007/978-1-4612-0303-2_33

Pires, P. W., Jackson, W. F., and Dorrance, A. M. (2015). Regulation of myogenic tone and structure of parenchymal arterioles by hypertension and the mineralocorticoid receptor. Am. J. Physiol. Heart Circ. Physiol. 309, H127H136.

Pomilio, C., Gorojod, R. M., Riudavets, M., Vinuesa, A., Presa, J., Gregosa, A., et al. (2020). Microglial autophagy is impaired by prolonged exposure to betaamyloid peptides: evidence from experimental models and Alzheimer's disease patients. Geroscience 42, 613-632. doi: 10.1007/s11357-02000161-9

Pomilio, C., Pavia, P., Gorojod, R. M., Vinuesa, A., Alaimo, A., Galvan, V., et al. (2016). Glial alterations from early to late stages in a model of Alzheimer's disease: evidence of autophagy involvement in Abeta internalization. Hippocampus 26, 194-210. doi: 10.1002/hipo.22503

Raichle, M. E. (2015). The restless brain: how intrinsic activity organizes brain function. Philos. Trans. R. Soc. Lond. B Biol. Sci. 370:20140172. doi: 10.1098/ rstb.2014.0172

Rivera-Rivera, L. A., Cody, K. A., Eisenmenger, L., Cary, P., Rowley, H. A., Carlsson, C. M., et al. (2020). Assessment of vascular stiffness in the internal carotid artery proximal to the carotid canal in Alzheimer's disease using pulse wave velocity from low rank reconstructed $4 \mathrm{D}$ flow MRI. J. Cereb. Blood Flow Metab. doi: 10.1177/0271678X20910302 [Epub ahead of print].

Roberts, J., Kahle, M. P., and Bix, G. J. (2012). Perlecan and the blood-brain barrier: Beneficial proteolysis? Front. Pharmacol. 3:155. doi: 10.3389/fphar.2012. 00155

Rodriguez-Iturbe, B., Pons, H., and Johnson, R. J. (2017). Role of the immune system in hypertension. Physiol. Rev. 97, 1127-1164.

Rom, S., Heldt, N. A., Gajghate, S., Seliga, A., Reichenbach, N. L., and Persidsky, Y. (2020). Hyperglycemia and advanced glycation end products disrupt BBB and promote occludin and claudin-5 protein secretion on extracellular microvesicles. Sci. Rep. 10:7274.

Rosenegger, D. G., Tran, C. H., Wamsteeker Cusulin, J. I., and Gordon, G. R. (2015). Tonic local brain blood flow control by astrocytes independent of phasic neurovascular coupling. J. Neurosci. 35, 13463-13474. doi: 10.1523/jneurosci. $1780-15.2015$
Ross, A. E., Nguyen, M. D., Privman, E., and Venton, B. J. (2014). Mechanical stimulation evokes rapid increases in extracellular adenosine concentration in the prefrontal cortex. J. Neurochem. 130, 50-60. doi: 10.1111/jnc.12711

Rothwell, P. M. (2010). Limitations of the usual blood-pressure hypothesis and importance of variability, instability, and episodic hypertension. Lancet 375, 938-948. doi: 10.1016/s0140-6736(10)60309-1

Rothwell, P. M., Howard, S. C., Dolan, E., O’Brien, E., Dobson, J. E., Dahlof, B., et al. (2010). Effects of beta blockers and calcium-channel blockers on withinindividual variability in blood pressure and risk of stroke. Lancet Neurol. 9, 469-480. doi: 10.1016/s1474-4422(10)70066-1

Royea, J., Zhang, L., Tong, X. K., and Hamel, E. (2017). Angiotensin IV receptors mediate the cognitive and cerebrovascular benefits of losartan in a mouse model of Alzheimer's disease. J. Neurosci. 37, 5562-5573. doi: 10.1523/jneurosci.032917.2017

Rungta, R. L., Chaigneau, E., Osmanski, B. F., and Charpak, S. (2018). Vascular Compartmentalization of Functional Hyperemia from the Synapse to the Pia. Neuron 99, 362-375.e4.

Ryskamp, D. A., Witkovsky, P., Barabas, P., Huang, W., Koehler, C., Akimov, N. P., et al. (2011). The polymodal ion channel transient receptor potential vanilloid 4 modulates calcium flux, spiking rate, and apoptosis of mouse retinal ganglion cells. J. Neurosci. 31, 7089-7101. doi: 10.1523/jneurosci.0359-11.2011

Sadekova, N., Iulita, M. F., Vallerand, D., Muhire, G., Bourmoum, M., Claing, A., et al. (2018). Arterial stiffness induced by carotid calcification leads to cerebral gliosis mediated by oxidative stress. J. Hypertens. 36, 286-298. doi: 10.1097/hjh. 0000000000001557

Sagare, A. P., Bell, R. D., Zhao, Z., Ma, Q., Winkler, E. A., Ramanathan, A., et al. (2013). Pericyte loss influences Alzheimer-like neurodegeneration in mice. Nat. Commun. 4:2932.

Santisteban, M. M., Ahn, S. J., Lane, D., Faraco, G., Garcia-Bonilla, L., Racchumi, G., et al. (2020). Endothelium-macrophage crosstalk mediates blood-brain barrier dysfunction in hypertension. Hypertension 76, 795-807. doi: 10.1161/ hypertensionaha.120.15581

Santisteban, M. M., and Iadecola, C. (2018). Hypertension, dietary salt and cognitive impairment. J. Cereb. Blood Flow Metab. 38, 2112-2128. doi: 10.1177/ $0271678 \times 18803374$

Schillaci, G., Bilo, G., Pucci, G., Laurent, S., Macquin-Mavier, I., Boutouyrie, P., et al. (2012). Relationship between short-term blood pressure variability and large-artery stiffness in human hypertension: findings from 2 large databases. Hypertension 60, 369-377. doi: 10.1161/hypertensionaha.112.197491

Seki, T., Goto, K., Kiyohara, K., Kansui, Y., Murakami, N., Haga, Y., et al. (2017). Downregulation of Endothelial Transient Receptor Potential Vanilloid Type 4 Channel and Small-Conductance of Ca2+-Activated $\mathrm{K}+$ Channels Underpins Impaired Endothelium-Dependent Hyperpolarization in Hypertension. Hypertension 69, 143-153. doi: 10.1161/hypertensionaha.116. 07110

Shams, S., Martola, J., Granberg, T., Li, X., Shams, M., Fereshtehnejad, S. M., et al. (2015). Cerebral microbleeds: different prevalence, topography, and risk factors depending on dementia diagnosis-the Karolinska Imaging Dementia Study. AJNR Am. J. Neuroradiol. 36, 661-666. doi: 10.3174/ajnr.a4176

Shigetomi, E., Saito, K., Sano, F., and Koizumi, S. (2019). Aberrant calcium signals in reactive astrocytes: a key process in neurological disorders. Int. J. Mol. Sci. 20:996. doi: 10.3390/ijms20040996

Shiota, S., Takekawa, H., Matsumoto, S. E., Takeda, K., Nurwidya, F., Yoshioka, Y., et al. (2013). Chronic intermittent hypoxia/reoxygenation facilitate amyloidbeta generation in mice. J. Alzheimers Dis. 37, 325-333. doi: 10.3233/jad130419

Silverman, A., and Petersen, N. H. (2020). Physiology, Cerebral Autoregulation. Treasure Island, FL: StatPearls.

Simard, M., Arcuino, G., Takano, T., Liu, Q. S., and Nedergaard, M. (2003). Signaling at the gliovascular interface. J. Neurosci. 23, 9254-9262. doi: 10.1523/ jneurosci.23-27-09254.2003

Skoog, I., Lernfelt, B., Landahl, S., Palmertz, B., Andreasson, L. A., Nilsson, L., et al. (1996). 15-year longitudinal study of blood pressure and dementia. Lancet 347, 1141-1145. doi: 10.1016/s0140-6736(96)90608-x

Sofroniew, M. V. (2015). Astrocyte barriers to neurotoxic inflammation. Nat. Rev. Neurosci. 16, 249-263. doi: 10.1038/nrn3898

Sofroniew, M. V., and Vinters, H. V. (2010). Astrocytes: biology and pathology. Acta Neuropathol. 119, 7-35. doi: 10.1007/s00401-009-0619-8 
Sonkusare, S. K., Bonev, A. D., Ledoux, J., Liedtke, W., Kotlikoff, M. I., Heppner, T. J., et al. (2012). Elementary Ca2+ signals through endothelial TRPV4 channels regulate vascular function. Science 336, 597-601. doi: 10.1126/science. 1216283

Sprint Mind Investigators for the Sprint Research Group, Williamson, J. D., Pajewski, N. M., Auchus, A. P., Bryan, R. N., Chelune, G., et al. (2019). Effect of intensive vs standard blood pressure control on probable dementia: a randomized clinical trial. JAMA 321, 553-561.

Srinivasan, R., Huang, B. S., Venugopal, S., Johnston, A. D., Chai, H., Zeng, H., et al. (2015). $\mathrm{Ca}(2+)$ signaling in astrocytes from $\operatorname{Ip} 3 \mathrm{r} 2(-/-)$ mice in brain slices and during startle responses in vivo. Nat. Neurosci. 18, 708-717. doi: 10.1038/nn.4001

Stefanovic, M., Puchulu-Campanella, E., Kodippili, G., and Low, P. S. (2013). Oxygen regulates the band 3-ankyrin bridge in the human erythrocyte membrane. Biochem. J. 449, 143-150. doi: 10.1042/bj20120869

Stevens, S. L., McManus, R. J., and Stevens, R. J. (2019). The utility of long-term blood pressure variability for cardiovascular risk prediction in primary care. J. Hypertens. 37, 522-529. doi: 10.1097/hjh.0000000000001923

Stevens, S. L., Wood, S., Koshiaris, C., Law, K., Glasziou, P., Stevens, R. J., et al. (2016). Blood pressure variability and cardiovascular disease: systematic review and meta-analysis. BMJ 354:i4098. doi: 10.1136/bmj.i4098

Su, J., Manisty, C., Parker, K. H., Simonsen, U., Nielsen-Kudsk, J. E., Mellemkjaer, S., et al. (2017). Wave intensity analysis provides novel insights into pulmonary arterial hypertension and chronic thromboembolic pulmonary hypertension. J. Am. Heart Assoc. 6:e006679.

Suadicani, S. O., Iglesias, R., Wang, J., Dahl, G., Spray, D. C., and Scemes, E. (2012). ATP signaling is deficient in cultured Pannexin1-null mouse astrocytes. Glia 60, 1106-1116. doi: 10.1002/glia.22338

Sweeney, M. D., Zhao, Z., Montagne, A., Nelson, A. R., and Zlokovic, B. V. (2019). Blood-brain barrier: from physiology to disease and back. Physiol. Rev. 99, 21-78. doi: 10.1152/physrev.00050.2017

Sweet, J. G., Chan, S. L., and Cipolla, M. J. (2015). Effect of hypertension and carotid occlusion on brain parenchymal arteriole structure and reactivity. J. Appl. Physiol. 119, 817-823. doi: 10.1152/japplphysiol.00467.2015

Tajada, S., Moreno, C. M., O’Dwyer, S., Woods, S., Sato, D., Navedo, M. F., et al. (2017). Distance constraints on activation of TRPV4 channels by AKAP150bound PKCalpha in arterial myocytes. J. Gen. Physiol. 149, 639-659. doi: 10.1085/jgp.201611709

Tanaka, L. Y., and Laurindo, F. R. M. (2017). Vascular remodeling: a redoxmodulated mechanism of vessel caliber regulation. Free Radic. Biol. Med. 109, 11-21. doi: 10.1016/j.freeradbiomed.2017.01.025

Tarantini, S., Tucsek, Z., Valcarcel-Ares, M. N., Toth, P., Gautam, T., Giles, C. B., et al. (2016). Circulating IGF-1 deficiency exacerbates hypertension-induced microvascular rarefaction in the mouse hippocampus and retrosplenial cortex: implications for cerebromicrovascular and brain aging. Age 38, 273-289. doi: 10.1007/s11357-016-9931-0

Thesen, T., Leontiev, O., Song, T., Dehghani, N., Hagler, D. J. Jr., et al. (2012). Depression of cortical activity in humans by mild hypercapnia. Hum. Brain Mapp. 33, 715-726. doi: 10.1002/hbm.21242

Thomsen, M. S., Routhe, L. J., and Moos, T. (2017). The vascular basement membrane in the healthy and pathological brain. J. Cereb. Blood Flow Metab. 37, 3300-3317. doi: 10.1177/0271678x177 22436

Thrane, A. S., Rangroo Thrane, V., Zeppenfeld, D., Lou, N., Xu, Q., Nagelhus, E. A., et al. (2012). General anesthesia selectively disrupts astrocyte calcium signaling in the awake mouse cortex. Proc. Natl. Acad. Sci. U.S.A. 109, 18974-18979. doi: 10.1073/pnas.1209448109

Tian, P., Teng, I. C., May, L. D., Kurz, R., Lu, K., Scadeng, M., et al. (2010). Cortical depth-specific microvascular dilation underlies laminar differences in blood oxygenation level-dependent functional MRI signal. Proc. Natl. Acad. Sci. U.S.A. 107, 15246-15251. doi: 10.1073/pnas.1006735107

Toth, P., Tarantini, S., Csiszar, A., and Ungvari, Z. (2017). Functional vascular contributions to cognitive impairment and dementia: mechanisms and consequences of cerebral autoregulatory dysfunction, endothelial impairment, and neurovascular uncoupling in aging. Am. J. Physiol. Heart Circ. Physiol. 312, $\mathrm{H} 1-\mathrm{H} 20$.

Toth, P., Tucsek, Z., Sosnowska, D., Gautam, T., Mitschelen, M., Tarantini, S., et al. (2013). Age-related autoregulatory dysfunction and cerebromicrovascular injury in mice with angiotensin II-induced hypertension. J. Cereb. Blood Flow Metab. 33, 1732-1742. doi: 10.1038/jcbfm.2013.143

Tong, X. K., Lecrux, C., Rosa-Neto, P., and Hamel, E. (2012). Age-dependent rescue by simvastatin of Alzheimer's disease cerebrovascular and memory deficits. $J$. Neurosci. 32, 4705-4715. doi: 10.1523/JNEUROSCI.0169-12.2012

Touyz, R. M., Alves-Lopes, R., Rios, F. J., Camargo, L. L., Anagnostopoulou, A., Arner, A., et al. (2018). Vascular smooth muscle contraction in hypertension. Cardiovasc. Res. 114, 529-539.

Tran, C. H., and Gordon, G. R. (2015). Astrocyte and microvascular imaging in awake animals using two-photon microscopy. Microcirculation 22, 219-227. doi: $10.1111 / \mathrm{micc} .12188$

Tran, C. H. T., Peringod, G., and Gordon, G. R. (2018). Astrocytes integrate behavioral state and vascular signals during functional hyperemia. Neuron 100 , 1133-1148.e3.

Trigiani, L. J., Royea, J., Lacalle-Aurioles, M., Tong, X. K., and Hamel, E. (2018). Pleiotropic benefits of the angiotensin receptor blocker candesartan in a mouse model of Alzheimer disease. Hypertension 72, 1217-1226. doi: 10.1161/ hypertensionaha.118.11775

Tsien, R. Y. (1988). Fluorescence measurement and photochemical manipulation of cytosolic free calcium. Trends Neurosci. 11, 419-424. doi: 10.1016/01662236(88)90192-0

Tsien, R. Y. (1989). Fluorescence ratio imaging of dynamic intracellular signals. Acta Physiol. Scand. Suppl. 582:6.

Tully, P. J., Yano, Y., Launer, L. J., Kario, K., Nagai, M., Mooijaart, S. P., et al. (2020). Association between blood pressure variability and cerebral small-vessel disease: a systematic review and meta-analysis. J. Am. Heart Assoc. 9:e013841.

Tyurikova, O., Zheng, K., Rings, A., Drews, A., Klenerman, D., and Rusakov, D. A. (2018). Monitoring $\mathrm{Ca}(2+)$ elevations in individual astrocytes upon local release of amyloid beta in acute brain slices. Brain Res. Bull. 136, 85-90. doi: 10.1016/j.brainresbull.2016.12.007

Tzeng, Y. C., Lucas, S. J., Atkinson, G., Willie, C. K., and Ainslie, P. N. (2010). Fundamental relationships between arterial baroreflex sensitivity and dynamic cerebral autoregulation in humans. J. Appl. Physiol. 108, 1162-1168. doi: 10. 1152/japplphysiol.01390.2009

Vanlandewijck, M., He, L., Mae, M. A., Andrae, J., Ando, K., Del Gaudio, F., et al. (2018). A molecular atlas of cell types and zonation in the brain vasculature. Nature 554, 475-480. doi: 10.1038/nature25739

Velasco-Estevez, M., Rolle, S. O., Mampay, M., Dev, K. K., and Sheridan, G. K. (2020). Piezol regulates calcium oscillations and cytokine release from astrocytes. Glia 68, 145-160. doi: 10.1002/glia.23709

Verkhratsky, A., and Nedergaard, M. (2018). Physiology of astroglia. Physiol. Rev. 98, 239-389. doi: 10.1152/physrev.00042.2016

Verkhratsky, A., Parpura, V., Vardjan, N., and Zorec, R. (2019). Physiology of astroglia. Adv. Exp. Med. Biol. 1175, 45-91.

Vernooij, M. W., van der Lugt, A., Ikram, M. A., Wielopolski, P. A., Niessen, W. J., Hofman, A., et al. (2008). Prevalence and risk factors of cerebral microbleeds: the Rotterdam Scan Study. Neurology 70, 1208-1214. doi: 10.1212/01.wnl. 0000307750.41970.d9

Vinuesa, A., Bentivegna, M., Calfa, G., Filipello, F., Pomilio, C., Bonaventura, M. M., et al. (2019). Early exposure to a high-fat diet impacts on hippocampal plasticity: implication of microglia-derived exosome-like extracellular vesicles. Mol. Neurobiol. 56, 5075-5094. doi: 10.1007/s12035-018-1435-8

Virani, S. S., Alonso, A., Benjamin, E. J., Bittencourt, M. S., Callaway, C. W., Carson, A. P., et al. (2020). Heart disease and stroke statistics-2020 update: a report from the American heart association. Circulation 141, e139-e596.

Volpe, M., Battistoni, A., Rubattu, S., and Tocci, G. (2019). Hypertension in the elderly: which are the blood pressure threshold values? Eur. Heart J. 21, B105-B106.

Waki, H., Hendy, E. B., Hindmarch, C. C., Gouraud, S., Toward, M., Kasparov, S., et al. (2013). Excessive leukotriene B4 in nucleus tractus solitarii is prohypertensive in spontaneously hypertensive rats. Hypertension 61, 194-201. doi: 10.1161/hypertensionaha.112.192252

Waki, H., Liu, B., Miyake, M., Katahira, K., Murphy, D., Kasparov, S., et al. (2007). Junctional adhesion molecule-1 is upregulated in spontaneously hypertensive rats: evidence for a prohypertensive role within the brain stem. Hypertension 49, 1321-1327. doi: 10.1161/hypertensionaha.106.085589

Waki, H., Murphy, D., Yao, S. T., Kasparov, S., and Paton, J. F. (2006). Endothelial NO synthase activity in nucleus tractus solitarii contributes to hypertension in 
spontaneously hypertensive rats. Hypertension 48, 644-650. doi: 10.1161/01. hyp.0000238200.46085.c6

Walas, D., Nowicki-Osuch, K., Alibhai, D., von Linstow, Roloff, E., Coghill, J., et al. (2019). Inflammatory pathways are central to posterior cerebrovascular artery remodelling prior to the onset of congenital hypertension. J. Cereb. Blood Flow Metab. 39, 1803-1817. doi: 10.1177/0271678x18769180

Wang, Y., DelRosso, N. V., Vaidyanathan, T. V., Cahill, M. K., Reitman, M. E., Pittolo, S., et al. (2019a). Accurate quantification of astrocyte and neurotransmitter fluorescence dynamics for single-cell and populationlevel physiology. Nat. Neurosci. 22, 1936-1944. doi: 10.1038/s41593-0190492-2

Wang, Y., Liang, H., Luo, Y., Zhou, Y., Jin, L., Wang, S., et al. (2019b). History of hypertension is associated With MR Hypoperfusion in Chinese inpatients With DWI-negative TIA. Front. Neurol. 10:867. doi: 10.3389/fneur.2019.00867

Wang, Y., and Venton, B. J. (2019). Comparison of spontaneous and mechanicallystimulated adenosine release in mice. Neurochem. Int. 124, 46-50. doi: 10.1016/ j.neuint.2018.12.007

Wei, H. S., Kang, H., Rasheed, I. Y., Zhou, S., Lou, N., Gershteyn, A., et al. (2016). Erythrocytes are oxygen-sensing regulators of the cerebral microcirculation. Neuron 91, 851-862. doi: 10.1016/j.neuron.2016.07.016

Wei, L., Mousawi, F., Li, D., Roger, S., Li, J., Yang, X., et al. (2019). Adenosine triphosphate release and P2 receptor signaling in piezol channel-dependent mechanoregulation. Front. Pharmacol. 10:1304.

Wight, T. N. (2008). Arterial remodeling in vascular disease: a key role for hyaluronan and versican. Front. Biosci. 13:4933-4937. doi: 10.2741/3052

Xing, C. Y., Tarumi, T., Meijers, R. L., Turner, M., Repshas, J., Xiong, L., et al. (2017). Arterial pressure, heart rate, and cerebral hemodynamics across the adult life span. Hypertension 69, 712-720. doi: 10.1161/hypertensionaha.116. 08986

Xu, H., Oliveira-Sales, E. B., McBride, F., Liu, B., Hewinson, J., Toward, M., et al. (2012). Upregulation of junctional adhesion molecule-A is a putative prognostic marker of hypertension. Cardiovasc. Res. 96, 552-560. doi: 10.1093/cvr/cvs273
Yamasaki, E., Thakore, P., Krishnan, V., and Earley, S. (2020). Differential expression of angiotensin II type 1 receptor subtypes within the cerebral microvasculature. Am. J. Physiol. Heart Circ. Physiol. 318, H461-H469.

Yang, Y., Vidensky, S., Jin, L., Jie, C., Lorenzini, I., Frankl, M., et al. (2011). Molecular comparison of GLT1+ and ALDH1L1+ astrocytes in vivo in astroglial reporter mice. Glia 59, 200-207. doi: 10.1002/glia. 21089

Zhang, L. Y., Pan, J., Mamtilahun, M., Zhu, Y., Wang, L., Venkatesh, A., et al. (2020). Microglia exacerbate white matter injury via complement C3/C3aR pathway after hypoperfusion. Theranostics 10, 74-90. doi: 10.7150/thno.35841

Zhang, Y., Sloan, S. A., Clarke, L. E., Caneda, C., Plaza, C. A., Blumenthal, P. D., et al. (2016). Purification and characterization of progenitor and mature human astrocytes reveals transcriptional and functional differences with mouse. Neuron 89, 37-53. doi: 10.1016/j.neuron.2015. 11.013

Zhou, S., Giannetto, M., DeCourcey, J., Kang, H., Kang, N., Li, Y., et al. (2019). Oxygen tension-mediated erythrocyte membrane interactions regulate cerebral capillary hyperemia. Sci. Adv. 5:eaaw4466. doi: 10.1126/sciadv.aaw4466

Zlokovic, B. V. (2005). Neurovascular mechanisms of Alzheimer's neurodegeneration. Trends Neurosci. 28, 202-208. doi: 10.1016/j.tins. 2005.02.001

Conflict of Interest: The authors declare that the research was conducted in the absence of any commercial or financial relationships that could be construed as a potential conflict of interest.

Copyright (c) 2020 Presa, Saravia, Bagi and Filosa. This is an open-access article distributed under the terms of the Creative Commons Attribution License (CC BY). The use, distribution or reproduction in other forums is permitted, provided the original author(s) and the copyright owner(s) are credited and that the original publication in this journal is cited, in accordance with accepted academic practice. No use, distribution or reproduction is permitted which does not comply with these terms. 